\title{
Systematic Review of Variations in Hyperthermic Intraperitoneal Chemotherapy (HIPEC) for Peritoneal Metastasis from Colorectal Cancer
}

\author{
Can Yurttas ${ }^{1,+}$, Giulia Hoffmann ${ }^{1,+}$, Alexander Tolios $^{2}{ }^{\mathbb{D}}$, Sebastian P. Haen ${ }^{3,4,5}$, \\ Matthias Schwab ${ }^{6,7,8}$, Ingmar Königsrainer ${ }^{1, \ddagger}$, Alfred Königsrainer ${ }^{1,4}$, Stefan Beckert ${ }^{1, \S}$ and
} Markus W. Löffler 1,3,4,6,*(D)

1 Department of General, Visceral and Transplant Surgery, University Hospital Tübingen, Hoppe-Seyler-Str. 3, D-72076 Tübingen, Germany; Can.Yurttas@med.uni-tuebingen.de (C.Y.); Giulia.Hoffmann@icloud.com (G.H.); Ingmar.Koenigsrainer@vlkh.net (I.K.);

Alfred.Koenigsrainer@med.uni-tuebingen.de (A.K.); sbeckert12@gmail.com (S.B.)

2 Department for Blood Group Serology and Transfusion Medicine, Medical University of Vienna, Währinger Gürtel 18-20, A-1090 Vienna, Austria; Alexander.Tolios@meduniwien.ac.at

3 Department of Immunology, Interfaculty Institute for Cell Biology, University of Tübingen, Auf der Morgenstelle 15, D-72076 Tübingen, Germany; Sebastian.Haen@med.uni-tuebingen.de

4 German Cancer Consortium (DKTK) and German Cancer Research Center (DKFZ) partner site Tübingen, Tübingen, Germany

5 Internal Medicine, Department for Oncology, Hematology, Immunology, Rheumatology and Pulmonology, University Hospital Tübingen, Otfried-Müller-Str. 10, D-72076 Tübingen, Germany

6 Department of Clinical Pharmacology, University Hospital Tübingen, Auf der Morgenstelle 8, D-72076 Tübingen, Germany; Matthias.Schwab@ikp-stuttgart.de

7 Department of Pharmacy and Biochemistry, University of Tübingen, Auf der Morgenstelle 8, D-72076 Tübingen, Germany

8 Dr. Margarete Fischer-Bosch-Institute of Clinical Pharmacology, Auerbachstr. 112, D-70376 Stuttgart, Germany

* Correspondence: Markus.Loeffler@uni-tuebingen.de; Tel.: +49-7071-29-80992

+ These authors contributed equally to this work.

$\ddagger$ Current address: Department of General-, Visceral- and Thoracic Surgery, Feldkirch Academic Hospital, Carinagasse 47, A-6807 Feldkirch, Austria.

$\S$ Current address: Department of General and Visceral Surgery, Schwarzwald-Baar Hospital, Klinikstr. 11, D-78052 Villingen-Schwenningen, Germany.

Received: 2 November 2018; Accepted: 10 December 2018; Published: 19 December 2018

\begin{abstract}
Background: Cytoreductive surgery (CRS), followed by hyperthermic intraperitoneal chemotherapy (HIPEC), combines radical surgery with abdominal heated chemotherapy, constituting a multimodal treatment approach. Since clear standards for HIPEC conduct in colorectal carcinoma (CRC) are lacking, we aimed to provide a comprehensive structured survey. Data sources and study eligibility criteria: A systematic literature search was performed in PubMed, with keywords "HIPEC" and "colorectal cancer", according to established guidelines. Articles were systematically screened, selecting 87 publications complemented by 48 publications identified through extended search for subsequent synthesis and evaluation, extracting inter alia details on used drugs, dosage, temperature, exposure times, and carrier solutions. Results: Compiled publications contained 171 reports on HIPEC conduct foremost with mitomycin $C$ and oxaliplatin, but also other drugs and drug combinations, comprising at least 60 different procedures. We hence provide an overview of interconnections between HIPEC protocols, used drugs and carrier solutions as well as their volumes. In addition, HIPEC temperatures and dosing benchmarks, as well as an estimate of in vivo resulting drug concentrations are demonstrated. Conclusions and implications: Owing to recent developments, HIPEC conduct and practices need to be reassessed. Unfortunately, imprecise and lacking reporting
\end{abstract}


is frequent, which is why minimal information requirements should be established for HIPEC and the introduction of final drug concentrations for comparability reasons seems sensible.

Keywords: hyperthermic intraperitoneal chemotherapy; colorectal carcinoma; peritoneal metastasis; cytoreductive surgery; systematic review; PRISMA

\section{Introduction}

Peritoneal metastasis (PM) can originate from a heterogeneous group of malignant tumors and frequently remains restricted to the peritoneal cavity. In the past, this condition was considered generally incurable and therefore as a palliative disease stage [1]. However, current multimodal treatment strategies comprising CytoReductive Surgery (CRS) and Hyperthermic IntraPEritoneal Chemotherapy (HIPEC) offer a promising therapy approach for selected patients. Depending on the extent of intra-abdominal tumor load, considerable survival benefits have been reported when compared to systemic chemotherapy alone, including a randomized controlled trial (RCT) [1,2].

This multimodal approach includes an ancillary treatment added to surgery, where a heated solution containing cytotoxic drugs is applied directly to the peritoneal cavity. This procedure called HIPEC is intended to destroy any remaining tumor cells after tumor removal. The underlying rationale is based on three theoretical considerations: (1) Surgical tumor debulking to expose residual tumor cells, due to poor tissue penetration of most cytotoxic drugs, (2) direct local administration of chemotherapy to the peritoneal cavity for homogeneous drug distribution, and (3) heated chemotherapy to enhance cytotoxicity [3].

In clinical practice, following CRS, the peritoneal cavity is filled with a heated carrier solution (CS) and cytotoxic drugs are subsequently added. A theoretical justification for this treatment is a compartmental effect termed "peritoneal-plasma barrier", suggesting that peritoneal malignancies are only insufficiently reachable by intravenous chemotherapy [4], such as a pharmacokinetic advantage assumed through high local drug concentrations combined with limited systemic exposure [5]. Hence, local administration of high-dosed cytotoxic drugs has been introduced to directly expose the peritoneal cavity, causing only confined systemic adverse effects. In colorectal cancer (CRC), the first formal RCT assessing the benefit added to surgery by using $30 \mathrm{~min}$ of oxaliplatin-based HIPEC, failed to show improved survival (PRODIGE 7; NCT00769405) [6,7]. In contrast, a current RCT in PM from ovarian cancer could establish improved survival, employing cisplatin HIPEC for $60 \mathrm{~min}$ in patients responding to carboplatin/paclitaxel [8]. Against this background, HIPEC is currently being reassessed, demanding comprehensive structured knowledge on respective treatment protocols published.

Hitherto, HIPEC was conducted with varying drugs, drug dosages and exposure times. Since this fact has been identified as a potential key issue and various calls for standardization in HIPEC are imminent [9-12], we performed a first of its kind comprehensive systematic literature review of the current state of the art in HIPEC for PM from CRC.

\section{Methods}

\subsection{Database Search and Source of Information}

We searched the MEDLINE database of the U.S. National library of Medicine through PubMed (www.ncbi.nlm.nih.gov/pubmed/) using the search terms "HIPEC" and "Colorectal Cancer" with Medical Subject headings (MeSH) (MEDLINE last accessed: 15 January 2017). This search therefore included the following search terms in MEDLINE: (hipec(All Fields) AND ("colorectal neoplasms"(MeSH Terms) OR ("colorectal"(All Fields) AND "neoplasms"(All Fields)) OR "colorectal neoplasms"(All Fields) OR ("colorectal"(All Fields) AND "cancer"(All Fields)) OR "colorectal cancer"(All Fields))) OR (("fever"(MeSH Terms) OR "fever"(All Fields) OR "hyperthermic"(All Fields)) AND intraperitoneal(All Fields) AND ("drug 
therapy"(Subheading) OR ("drug"(All Fields) AND "therapy"(All Fields)) OR "drug therapy"(All Fields) OR "chemotherapy"(All Fields) OR "drug therapy"(MeSH Terms) OR ("drug"(All Fields) AND "therapy"(All Fields)) OR "chemotherapy"(All Fields)) AND ("colorectal neoplasms"(MeSH Terms) OR ("colorectal"(All Fields) AND "neoplasms"(All Fields)) OR "colorectal neoplasms"(All Fields) OR ("colorectal"(All Fields) AND "cancer"(All Fields)) OR "colorectal cancer"(All Fields))).

We identified 397 publications, which were screened for suitability. From the remaining articles, 66 publications were excluded (due to being review type articles, non-English language, or describing animal models). The remaining 125 articles were individually assessed and screened for relevant information (i.e., any reports describing the clinical use of HIPEC after CRS in humans with PM of CRC origin) and another 38 publications were excluded due to a lack of relevance. Ultimately, 87 articles were included into subsequent evaluations and complemented by 48 additional publications, identified by screening review type articles and reference lists. This resulted in 135 publications in total, encompassing 171 reports on HIPEC conduct for CRC.

A PRISMA (Preferred Reporting Items for Systematic Reviews and Meta-Analyses) flow diagram detailing the literature research strategy is provided in Figure 1.

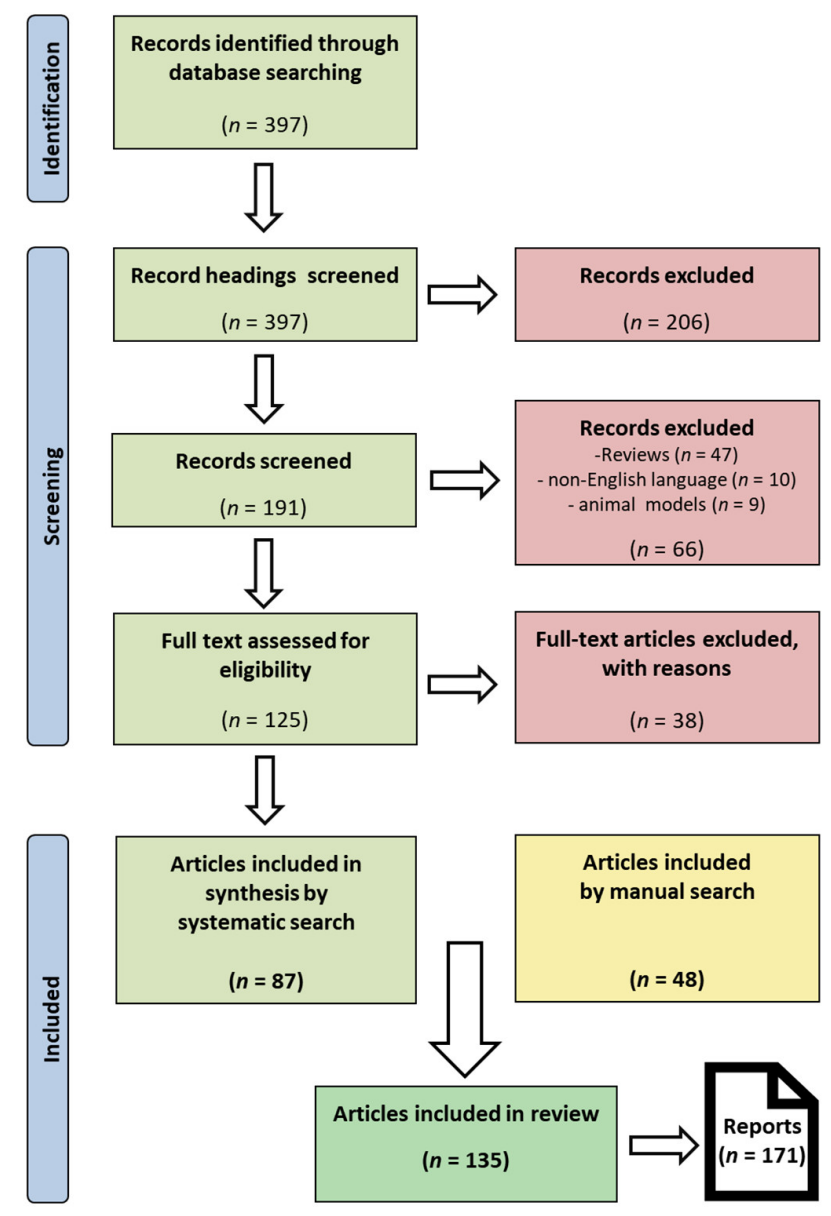

Figure 1. PRISMA (Preferred Reporting Items for Systematic Reviews and Meta-Analyses) flow diagram illustrating the literature search strategy: It maps the number of records identified, screened, included as well as excluded with respective reasons, conforming to PRISMA guidelines available at http:/ / prisma-statement.org. This systematic search was complemented by 48 manuscripts identified through manual search of review type articles and back searches from reference lists of included articles, resulting in 135 articles in total, containing 171 reports on HIPEC conduct. 


\subsection{Quality Assessment}

Quality assessment of the studies included was intentionally refrained from, since a meta-analysis of data was neither within the scope, nor considered appropriate based on the substantial differences observed. We instead intended to provide a systematic overview and description of the available literature on HIPEC treatment in CRC.

\subsection{Data Extraction}

Data was systematically extracted from all included publications, compiling the following information on HIPEC treatment when disclosed: Drug used (international nonproprietary name; INN, if applicable); drug dosage; type of matrix (diluent; carrier solution) used for peritoneal perfusion; volume of diluent in L; duration ( $\mathrm{min}$ ) and temperature of HIPEC in ${ }^{\circ} \mathrm{C}$; number of patients treated; and duration of study (year (initiation) to year (end)), date of publication (month/year), and concomitant treatments (EPIC, i.v. chemotherapy). Authors of primary research articles were not contacted in case of missing information. Respective compiled data is provided in Tables S1-S9.

\subsection{Data Synthesis}

Data synthesis was performed using narrative methods. Further, data was compiled, tabulated, and outlined using suitable software (Microsoft Office; Microsoft, Redmond, WA, USA), according to the terms given under data extraction. For representation purposes, basic descriptive statistics were employed where appropriate. For depiction of geographical locations, an amMap JavaScript Maps was used (www.amcharts.com). Further statistical analyses were performed using the R software in the version 3.5.1 [13] as well as the packages dplyr in the version 0.7.6 [14], ggplot2 in the version 3.0.0 [15], tidyverse in the version 1.2.1 [16], plyr in the version 1.8.4 [17], ggpubr in the version 0.1.8 [18] and figures were created. Restrictions of data included may apply, as mentioned in respective figure captions.

\subsection{Compliance with Applicable Guidelines}

When applicable and appropriate to the scope of this review, respective guidelines were adhered to [19]. PRISMA guidelines have been consulted and transparent and reproducible methodology was implemented (Figure 1) [20]. Basic data assessed for the purposes of this review can be obtained in Tables S1-S9. A PRISMA checklist is provided in Table S10. A formal registration and systematic review protocol were omitted.

\section{Results}

\subsection{Literature Search and Evaluation}

Our search strategy identified 397 publications of which about $70 \%$ were initially excluded due to insufficiently matching our search criteria and another 38 articles after accessing the full text. Altogether, 135 publications, comprising articles identified by systematic as well as manual search were compiled from the scientific literature, adding up to 171 reports on HIPEC conduct performed for PM of CRC origin (Figure 1; Tables S1-S9).

Already at first examination, the obtained results concerning HIPEC drugs, drug dosage, duration, and diluents showed considerable heterogeneity and lacking consistency (Figure 2). Clinical conduct of HIPEC further demonstrated clearly discernible dependencies in various instances. For example, the lead off protocol establishing a dosage benchmarked in $\mathrm{mg} / \mathrm{m}^{2}$ with mitomycin (MMC), published in 2001 by Witkamp et al., introduced a trend-setting practice (Table S1) [21]. Of note, this protocol administered $35 \mathrm{mg} / \mathrm{m}^{2} \mathrm{MMC}$ fractionated over $90 \mathrm{~min}$ and was featured in the first ever RCT testing CRS and HIPEC versus systemic chemotherapy [2]. 
a

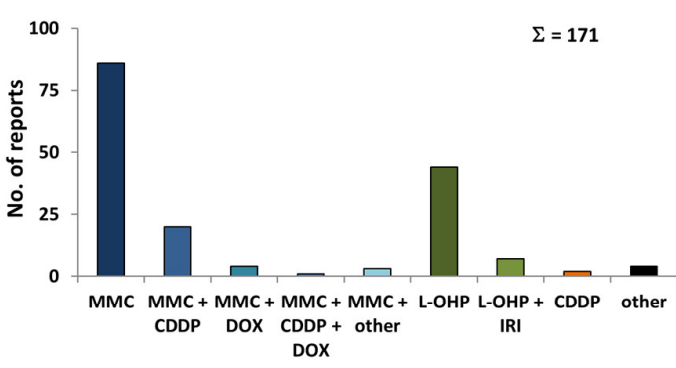

C

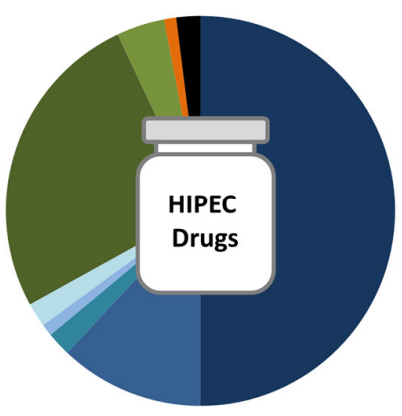

- MMC (50 \%)

- $M M C+\operatorname{CDDP}(12 \%)$

$\mathrm{MMC}+\mathrm{DOX}(2 \%)$

$M M C+C D D P+D O X(1 \%)$

MMC+other $(2 \%)$

- L-OHP (26\%)

L-OHP + IRI (4 \%)

- $\operatorname{CDDP}(1 \%)$

- other (2\%) b

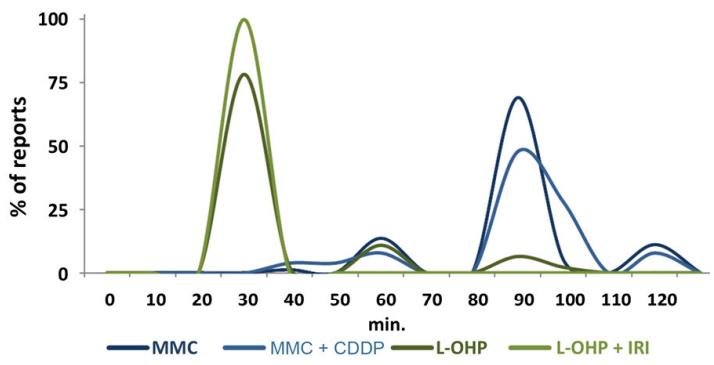

d

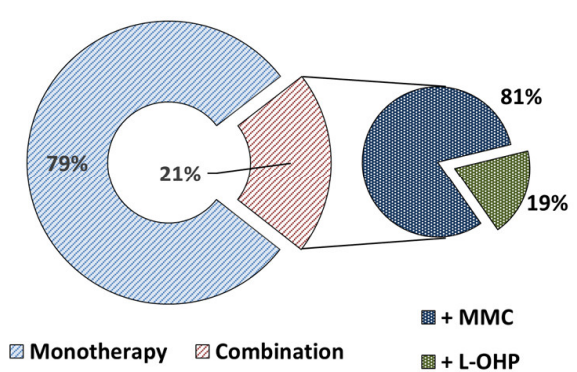

Monotherapy $\oslash$ Combination $\quad$ 通 + L-OHP

Figure 2. Drug use: (a) Bar chart of HIPEC (hyperthermic intraperitoneal chemotherapy) reports ( $n=171)$ with respective drugs or drug combinations. (b) Percentages of included reports on selected drugs and drug combinations plotted against HIPEC duration in minutes (x-axis). (c) Percentages of drugs and drug combinations among reports. (d) Percentages of drug mono- and combination therapies. Drug combinations were further subdivided into protocols using a drug combination with MMC or L-OHP. Abbreviations used: CDDP (cisplatin); DOX (doxorubicin); IRI (irinotecan); L-OHP (oxaliplatin); and MMC (mitomycin c).

The basic reported parameters, describing HIPEC conduct, were mainly the administered drugs and their dosage (using different ways of benchmarking), as well as the diluent/carrier solution (CS) used for peritoneal perfusion, respective volumes, and target temperatures as well as treatment duration. However, frequently reports on HIPEC conduct were fragmentary and relevant variables remained undisclosed (Tables S1-S8).

\subsection{Heterogeneity in HIPEC Conduct}

Multiple articles were published between 1994 and 2017 describing HIPEC with MMC or L-OHP in single and combined use for CRC, reporting trials conducted between 1981 and 2016 (Figure 3). In total, we identified 86 reports on HIPEC conduct with MMC as a monotherapy (Figure 2a, Table S1) [2,9,21-103]. We observed more than twenty different ways of dosing MMC, with additional variation in case further factors would be taken into account (Table S1). For MMC/cisplatin (CDDP) combinations, eleven different manners of dosing drugs were identified among 20 articles, published between 1992 and 2017 (Figure 2a, Table S2) [42,43,91,104-120]. In MMC/doxorubicin (DOX) combinations, we noticed three different reports considering drug dosage among merely four publications (Figure 2a, Table S3) [121-124]. An additional treatment protocol each was described for the combination of MMC with 5-fluorouracil (5-FU) [125], the active irinotecan (IRI) metabolite hydroxycamptothecin (HCPT) [126] and etoposide (ETO) [119] (Table S7). Using single-agent oxaliplatin (L-OHP), at least twelve different manners of drug dosing were described in 44 articles published between 2002 and 2017 (Table S4) [28,31-35,54,55,60,65,66,69,72,75,76,81,82,91,108,111,116, 121,127-148]. Between 2004 and 2016 seven articles were published, outlining four diverse ways of dosing a combination of L-OHP and IRI (Table S5) [32,83,134,140,144,149,150]. 

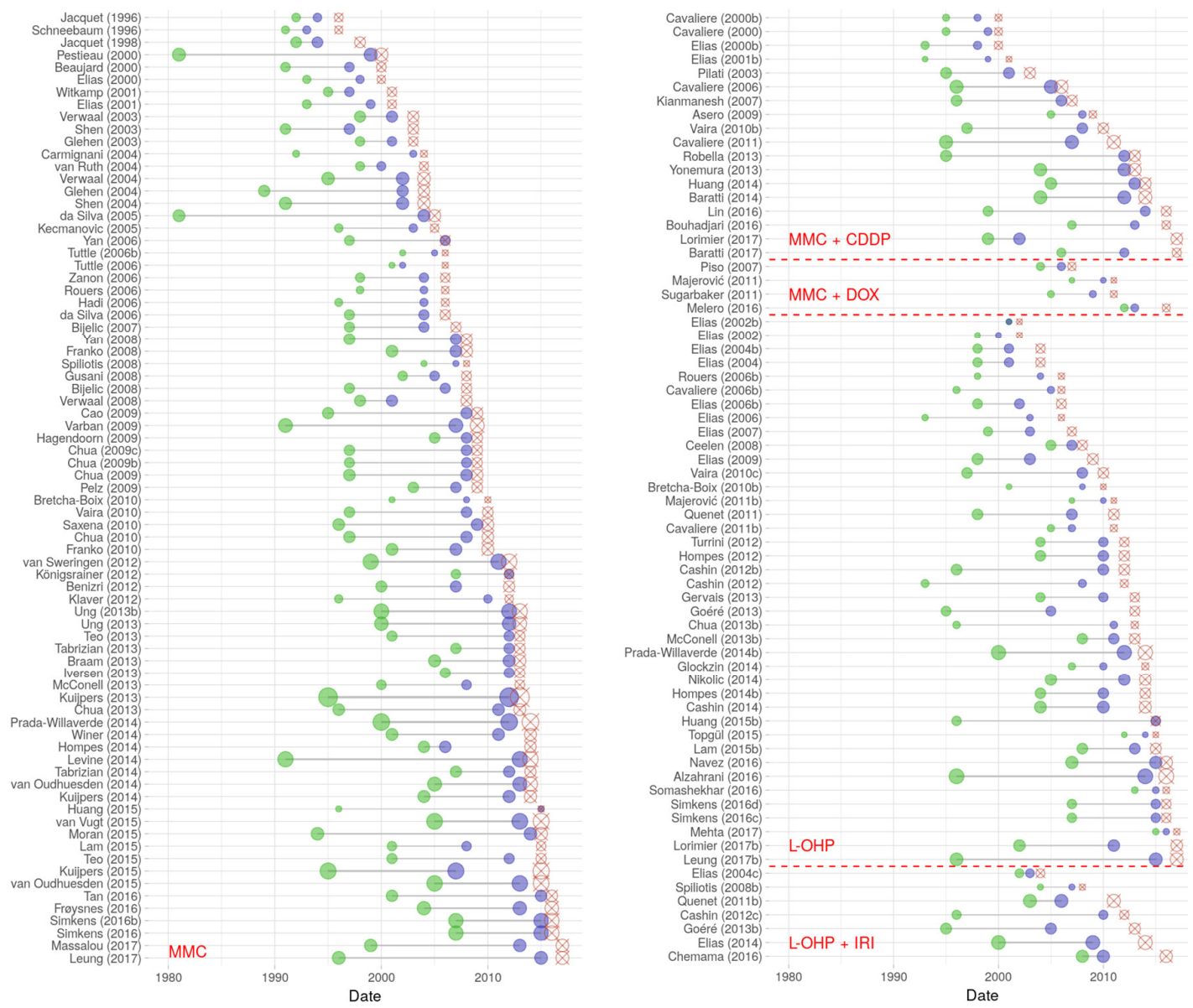

Figure 3. Trial conduct: The Lollipop plot depicts HIPEC clinical trials performed between 1981 and 2016 and published from 1994 to 2017 with different cytostatic drugs (only reports with $n>4$ patients and protocols containing MMC or L-OHP single drug or combinations were included). Green dots signify year of trial initiation, blue dots end of recruitment, red crossed markers point to publication dates. Symbols are $\mathrm{lg}$ scaled according to number of patients included in the respective study. Publications conform to annotations given in Tables S1-S5, with Arabic letters marking chronological order (if required). Abbreviations used: CDDP (cisplatin); DOX (doxorubicin); IRI (irinotecan); L-OHP (oxaliplatin); and MMC (mitomycin c).

Only two publications reported a CDDP-monotherapy described by two different treatment protocols (Table S6) [108,147]. Approaches using either Melphalan (L-PAM) [151], 5-FU [152,153], or IRI [139] as a monotherapy were also very uncommon and have been reported only once or twice (Table S8). Furthermore, a single account describing a triple drug combination of MMC with CDDP and DOX in patients with disease refractory to prior HIPEC treatment was described [127].

Overall, we compiled descriptions of no less than 60 different HIPEC protocols, accounting only for drug choice and / or dosages administered, among the 171 descriptions of HIPEC conduct published over a 25-year period (1992-2017) (Tables S1-S8).

\subsection{Drugs Used for HIPEC in Peritoneal Metastasis from Colorectal Cancer}

We observed a considerable variety of cytotoxic drugs used for HIPEC in PM from CRC. About 2/3 of protocols used MMC as a monotherapy (50\%) [2,9,21-103] or combined with CDDP $(12 \%)[42,43,91,104-120]$, as well as infrequently combined with other drugs (Figure 2a,c, Tables S1-S3 and S7) [119,121-127]. As a monotherapy CDDP was insignificant in CRC (1\%) (Table S6) [108,147]. The second most frequently used drug was L-OHP mainly employed as a single-agent therapy (26\%; Figure 2a,c, Table S4) $[28,31-35,54,55,60,65,66,69,72,75,76,81,82,91,108,111,116,121,127-148]$ or 
combined with IRI (Table S5) $[32,83,134,140,144,149,150]$. Rarely, monotherapies with other drugs were mentioned (Table S8) [139,151-153].

\subsection{HIPEC Conduct with Mitomycin C (MMC)}

The most frequently used HIPEC drug MMC (Figure 2) was most commonly administered at $35 \mathrm{mg} / \mathrm{m}^{2}$, which was the case in $28 \%$ of protocols (Figure 4) $[2,9,27,31,34,41,46,53,54,61,63,64,72,81$, 82,89,91-94,96,98,99]. Administered drug doses ranged from 10 to $40 \mathrm{mg} / \mathrm{m}^{2}$ [21,76]. Additionally, alternative measures were employed using $\mathrm{mg}$, $\mathrm{mg} / \mathrm{L}$ and $\mathrm{mg} / \mathrm{kg}$ as a benchmark (Figure 4) $[47,49,70]$. In many protocols, inconsistent amounts of diluents were used, adding some variability (Figure 5). Exclusive to MMC, fractionated dosing subdivided into two or three-step drug administration during one single HIPEC session was reported (Table S1). This practice was adopted in about $30 \%$ of MMC-based protocols $[2,9,21,26,27,41,44-46,51,53,63,64,67,70,75,78-80,84,85,94,95,97-100]$.

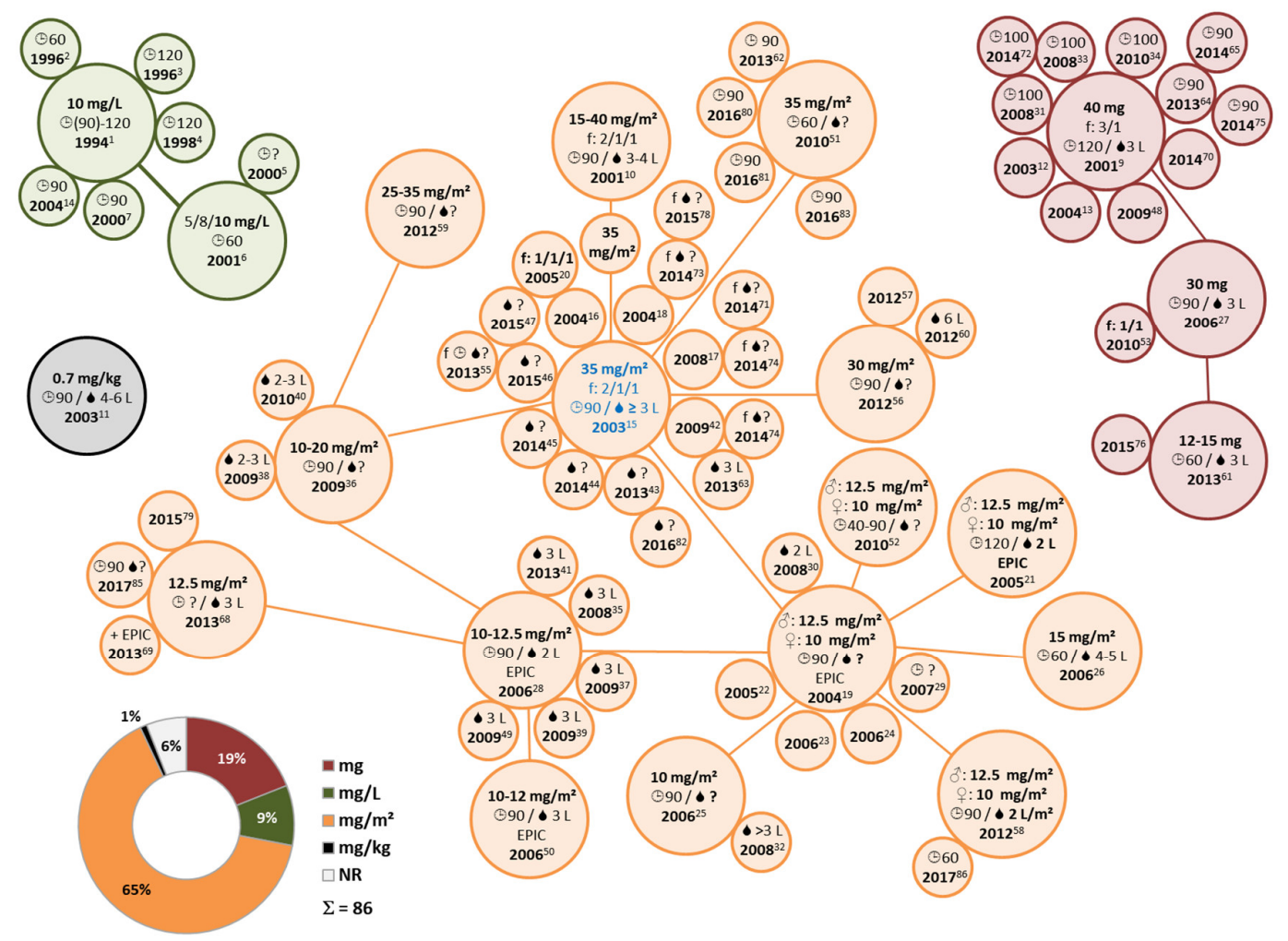

Figure 4. Overview of HIPEC protocols using MMC: Depiction of different drug dosages and measures thereof (pie chart with percentages) among protocols using MMC $(n=86)$. Connections and circle sizes are arbitrary and protocols were compiled manually, according to respective similarities. Related publications are annotated by superscript numbers, conforming to annotations given in Table S1. Publications reporting different protocols are shown multiple times, those without specific information (NR; not reported) are omitted. RCTs are marked in blue. Abbreviations and symbols: EPIC (Early postoperative intraperitoneal chemotherapy); $\mathrm{f}$ (fractionated, indicating shares of total dosage administered); MMC (mitomycin c); RCT (randomized controlled trial); $\bullet$ (amount of diluent); (다 (HIPEC duration); $\hat{\partial}$ (male) and + (female).

Another practice distinctive for MMC single-agent use was adjusting the drug dosage according to sex. Here, a dosage of $12.5 \mathrm{mg} / \mathrm{m}^{2}$ for men and a slightly lower dosage of $10.0 \mathrm{mg} / \mathrm{m}^{2}$ for women was employed, which was described in about $10 \%$ of reports (Table S1) $[23-25,28,30,40,50,52,59,68]$. More importantly in the publications actually reporting diluent amounts, once $1.0 \mathrm{~L}$ was reported [52], twice $2.0 \mathrm{~L}$ [25,59], and in two further publications $2.0 \mathrm{~L} / \mathrm{m}^{2}$ [23,68], which affects the resulting 
drug concentrations more relevantly than, for instance, the comparably modest sex specific adaptations suggested.

For a rough estimate of actual drug concentrations used during HIPEC, we imputed respective values if unavailable to us. Based on presumed average patient characteristics and assuming maximum concentrations, we estimated HIPEC drug concentrations and categorized the results according to drug solvents. In MMC, respective median concentrations resulted in about 7-13 $\mu \mathrm{g} / \mathrm{mL}$ (Figure 5).

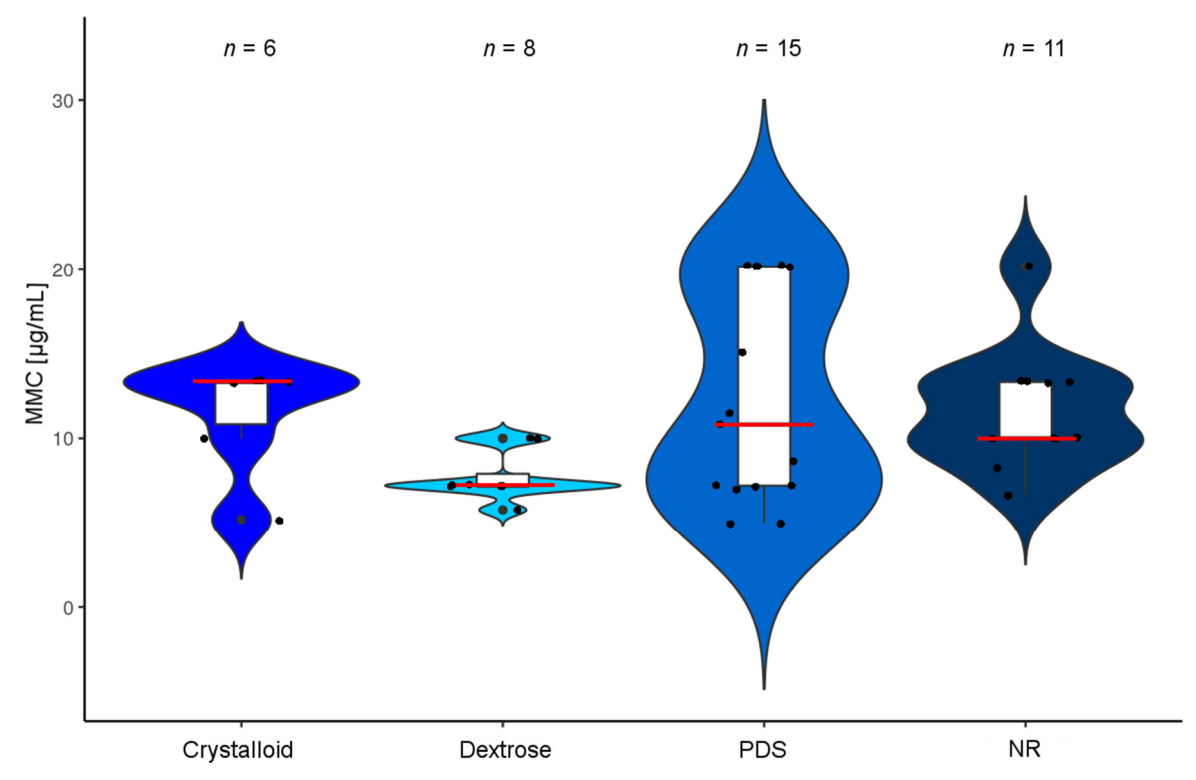

Figure 5. Drug concentration of MMC: The violin plot depicts concentrations of MMC as used in different HIPEC protocols. Protocols were categorized according to the matrix used to dilute drugs (crystalloid, dextrose, PDS or NR). Since there is lacking uniformity and for comparative reasons, we imputed data to a presumed average patient (with characteristics of $1.7 \mathrm{~m}$ height, $70 \mathrm{~kg}$ weight and $1.73 \mathrm{~m}^{2}$ body surface area). Further in the case of ambiguity values were maximized using the maximal drug amounts and the minimum diluent volumes reported. The red bars mark medians and white boxes interquartile range. Protocols with missing data or reporting $\leq 4$ patients were omitted. (Median drug concentrations ( $\mu \mathrm{g} / \mathrm{mL})$ : crystalloid: 13.3; Dextrose: 7.2; PDS: 10.8; NR: 10). Abbreviations used: MMC (mitomycin c); PDS (peritoneal dialysis solution); and NR (not reported).

\subsection{HIPEC Conduct with Oxaliplatin (L-OHP)}

The second most frequently used HIPEC drug was L-OHP, which was used according to $26 \%$ of reports (Figure 2c) $[28,31-35,54,55,60,65,66,69,72,75,76,81-83,91,108,111,116,121,127-150]$. With L-OHP a remarkable homogeneity concerning drug dosing was observed and all but four articles used $\mathrm{mg} / \mathrm{m}^{2}$ for benchmarking (Figure 6, Table S4). Obviously, when accounting for the dilution of drugs during abdominal perfusion, additional variability is introduced, yet many protocols reported using $2 \mathrm{~L} / \mathrm{m}^{2}$ as a benchmark, yielding an L-OHP concentration of $230 \mu \mathrm{g} / \mathrm{mL}$ [75,76,108,111,128-138,140-142,144,148] (Figure 7). An initial L-OHP dose finding study was published by Elias et al. in 2002 [131], establishing the prototype protocol. Accordingly, about $2 / 3$ of protocols with L-OHP monotherapy reported the use of $460 \mathrm{mg} / \mathrm{m}^{2} \mathrm{~L}-\mathrm{OHP}$ (Figure 6) [31-35,54,72,75,76,81,82,91,108,111,116,121,128-133,135-138,140, $141,144,148]$. Other protocols predominantly reported the use of lower amounts of L-OHP $[55,65,66,69$, $127,134,139,142,143,145,147]$. Of note, only one single publication reported administering an amount of $460 \mathrm{mg} / \mathrm{m}^{2} / \mathrm{L}$, adding up to a substantially increased concentration of L-OHP compared to most other protocols [121], yielding a concentration $795 \mu \mathrm{g} / \mathrm{mL}$ and resulting in an outlier. In the PRODIGE7 trial, L-OHP has been used with adjustments of the drug dosage according to the open or closed technique of HIPEC ( $360 \mathrm{mg} / \mathrm{m}^{2}$ or $460 \mathrm{mg} / \mathrm{m}^{2}$ in $2 \mathrm{~L} / \mathrm{m}^{2}$ body surface area, respectively) [7], yielding a drug concentration of $180 \mu \mathrm{g} / \mathrm{mL}$ and $230 \mu \mathrm{g} / \mathrm{mL} \mathrm{L-OHP,} \mathrm{respectively.}$ 


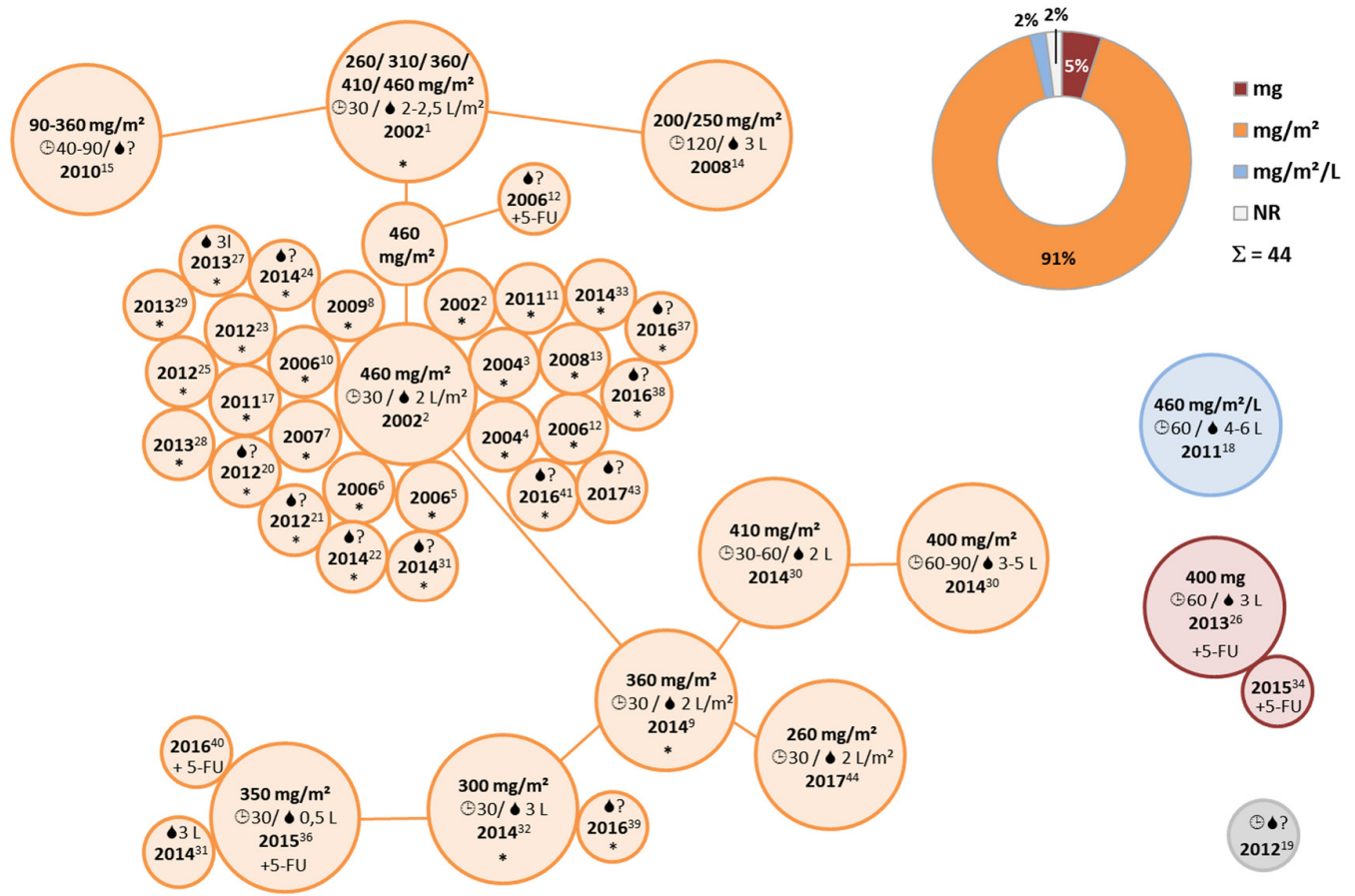

Figure 6. Overview of HIPEC protocols using L-OHP: Depiction of different drug dosages and measures thereof (pie chart with percentages) among protocols using L-OHP $(n=44)$. Connections and circle sizes are arbitrary and protocols were compiled manually, according to respective similarities. Related publications are annotated by superscript numbers, conforming to annotations in Table S4. Abbreviations and symbols: 5-FU (5-fluorouracil i.v.); ( amount of diluent); $\odot$ (duration of HIPEC); * (bidirectional protocol with 5-FU/Leucovorin); and L-OHP (oxaliplatin).

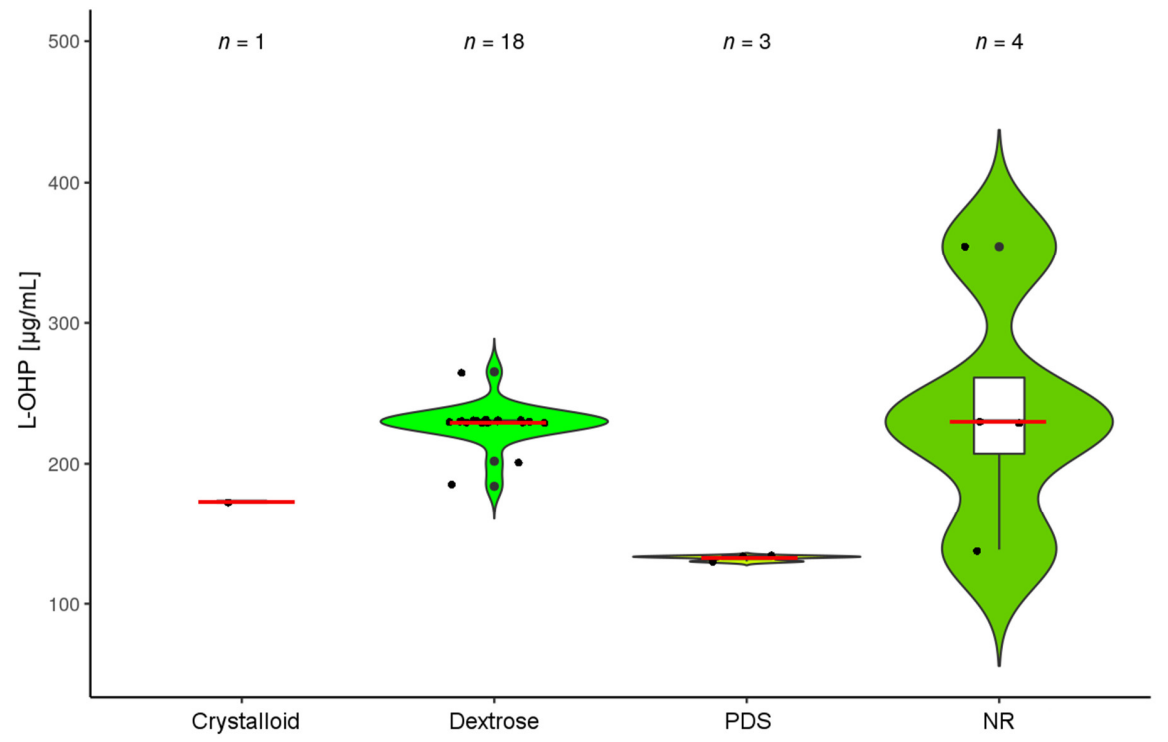

Figure 7. Drug concentration of L-OHP: The violin plot depicts concentrations of L-OHP, as used in different HIPEC protocols. Protocols were categorized according to the matrix used to dilute drugs (crystalloid, dextrose, PDS or NR). Since there is lacking uniformity and for comparative reasons, we imputed data to a presumed average patient (with characteristics of $1.7 \mathrm{~m}$ height, $70 \mathrm{~kg}$ weight and $1.73 \mathrm{~m}^{2}$ body surface area). Further, in case of ambiguity values were maximized using the maximal drug amounts and the minimum diluent volumes reported. The red bars mark medians and white boxes interquartile range. Protocols with missing data or reporting $\leq 4$ patients and the outlier [121] were omitted. (Median drug concentrations ( $\mu \mathrm{g} / \mathrm{mL}$ ): crystalloid: 173; Dextrose: 230; PDS: 133; NR: 230). Abbreviations used: L-OHP (oxaliplatin); PDS (peritoneal dialysis solution); and NR (not reported). 


\subsection{HIPEC Protocols Describing Combined Drug Use}

A substantial proportion of HIPEC protocols reported using cytotoxic drugs combined within the same solution (Figure 8). In this regard the most frequently employed combinations were MMC/CDDP $(n=20)[42,43,91,104-120]$, but also MMC/DOX $(n=4)$ [121-124] and L-OHP/IRI were mentioned ( $n=7$; Figure 2a) $[32,83,134,140,144,149,150]$, accounting for $21 \%$ of all HIPEC protocols (Figure 2d). Of those, about 4/5 included MMC and the remainder used L-OHP. Respective HIPEC protocols did not only feature different drugs, but also variable measures for benchmarking drug dosages (Figure 8). One report even lacked consistency regarding the benchmark measures for drug dosing. Here, $120 \mathrm{mg}$ were specified for MMC together with $200 \mathrm{mg} / \mathrm{m}^{2}$ for CDDP [114].
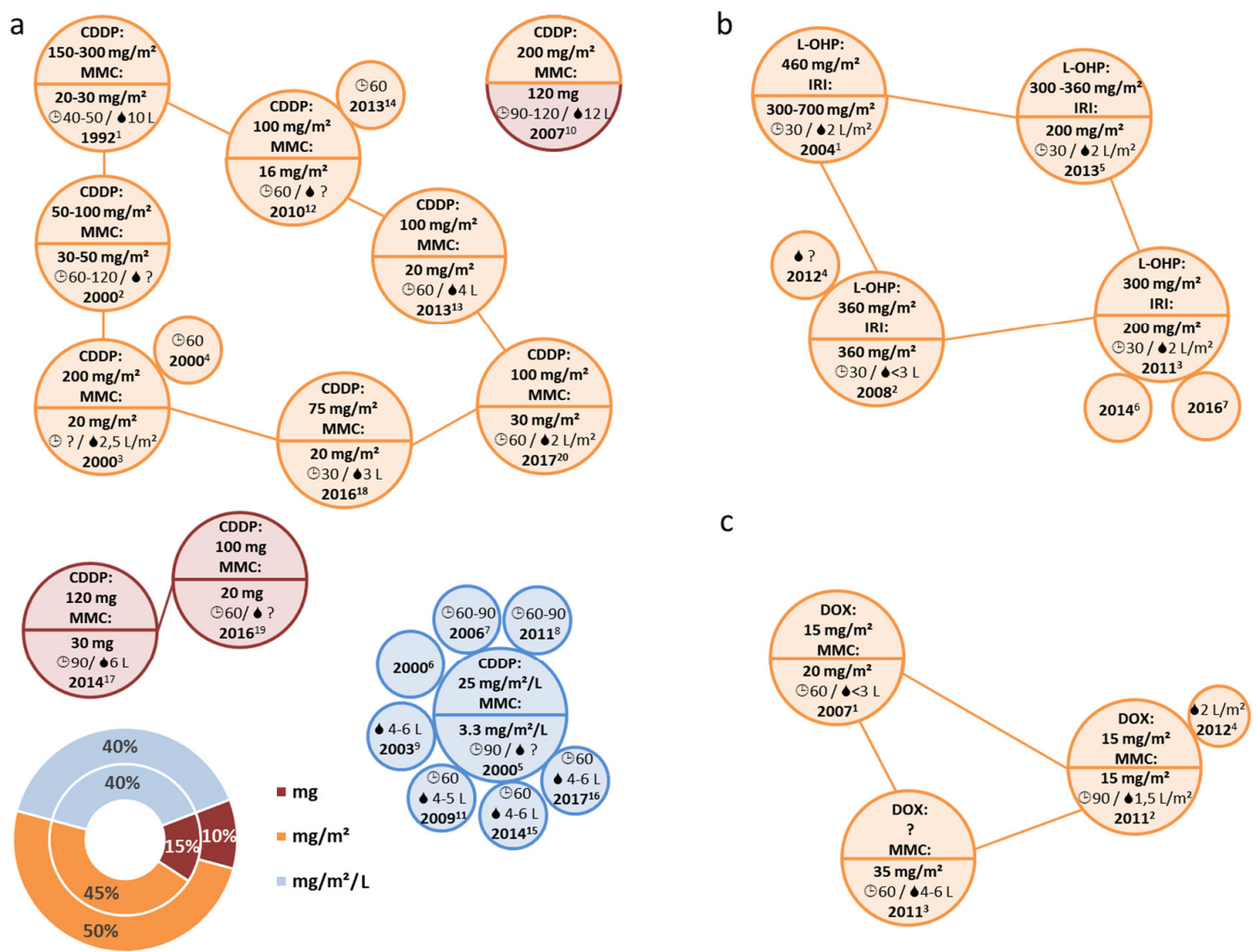

C

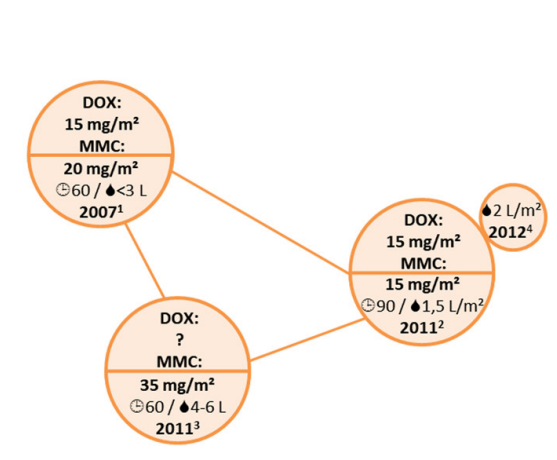

Figure 8. Overview of HIPEC protocols using drug combinations: (a) Depiction of different drug dosages and measures thereof (double pie chart with percentages) among protocols using CDDP/MMC combinations $(n=20)$. Related publications are annotated by superscript numbers, conforming to annotations in Table S2; further in (b) protocols using L-OHP combined with IRI $(n=7)$ are annotated conforming to superscript numbers in Table S5; as well as in (c) protocols using MMC combined with DOX $(n=4)$ conforming to superscript numbers in Table S3. All connections and circle sizes are arbitrary and protocols were compiled manually, according to respective similarities. Abbreviations and symbols: $\bullet$ (amount of diluent); and $\odot$ (HIPEC duration).

\subsection{Uncommon HIPEC Drugs}

Various cytostatic drugs were infrequently used, including CDDP monotherapy $[108,147]$ (Table S6) and a number of other drugs limited to one or two publications only (5-FU/IRI/L-PAM; Table S8) [139,151-153]. Considering rare drug combinations, HIPEC conduct with mixtures of MMC and ETO, 5-FU as well as HCPT were reported (Table S7) [119,125,126]. A triple drug combination was an exemption [127]. Of note, HIPEC protocols with triple drug combinations (MMC + CDDP + 5-FU) have recently been introduced for PM from gastric cancer [154]. 


\subsection{Differences in Exposure Times to Cytotoxic Drugs}

The overall exposure time of the peritoneum to cytotoxic drugs ranged between $20 \mathrm{~min}$ and $120 \mathrm{~min}[67,152]$. A relatively short duration of $30 \mathrm{~min}$ was very common for L-OHP (Figure $2 \mathrm{~b}$, Tables S4 and S5). This was the case both in L-OHP single-agent HIPEC (80\%) [32-35,54,55, $66,72,75,76,81,82,91,108,111,116,127-142,144,145,148]$ (Table S4), as well as in combination with IRI $(100 \%)[32,83,134,140,144,149,150]$ (Figure 2b, Table S5). This differs with MMC single-agent or combined use with CDDP (Figure 2b, Tables S1 and S2), where HIPEC duration was at least 90 min in about $78 \%$ of reports $[2,9,21-23,25-27,29,30,32-41,44-54,56-60,62-64,67,70,72,73,75-77,79-85,89,92-102]$. A long exposure in L-OHP protocols was rather uncommon (10\%) and extended exposure times of $1 \mathrm{~h}$ and beyond were mostly reported in dose finding studies, with treatments lasting for up to $2 \mathrm{~h}$ [146]. Particularly with infrequently employed drugs (Tables S6 and S8) $[108,139,147,151-153]$ or in respective drug combinations (Table S7) [119,125-127], a considerable variability and ambiguity prevailed, suggesting a particularly experimental setting.

\subsection{Differences in Benchmarking Applied Drug Dosages}

The publications included in our survey originated from four continents (Europe, Asia, North America, and Australia) and included at least 23 different countries, featuring roughly ten thousand CRC patients (Figure 9a).

a

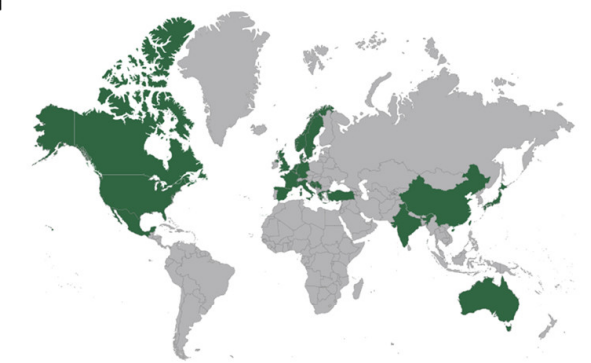

C

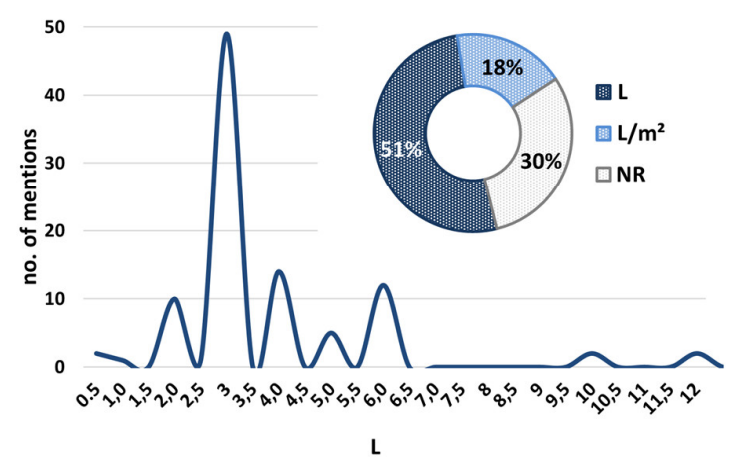

b

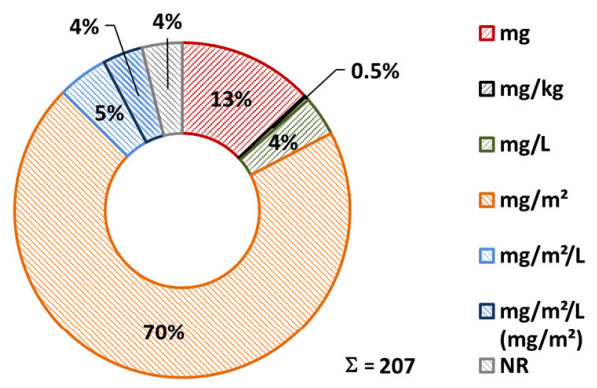

d

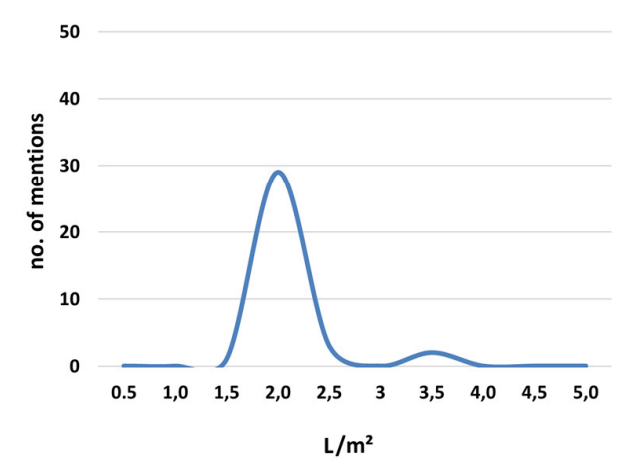

Figure 9. Overview of manuscript provenience, dosage specifications, and volumes of diluents: (a) Provenience of authors reporting HIPEC conduct in PM from CRC (b) Designations used for benchmarking drug dosages. (c) Volumes of diluents used for abdominal perfusion in L (x-axis) plotted against the number of mentions in publications (y-axis). The pie chart depicts percentages of HIPEC reports mentioning diluent volumes in $\mathrm{L}, \mathrm{L} / \mathrm{m}^{2}$, or with no further specification (NR). (d) Volumes of diluent used in $\mathrm{L} / \mathrm{m}^{2}$ (x-axis) plotted against the number of mentions in publications (y-axis). Numbers were rounded to one half of a percent. Abbreviations used: NR (not reported).

As respective standards for reporting drug dosages in HIPEC are lacking, we assessed all HIPEC protocols in this regard. Considering the substantial variability in HIPEC conduct and manifold drugs 
and their combinations, such as inconsistent drug dosing even within the very same publication [114], we chose to consider each reported benchmark designation separately. This approach yielded 207 designations altogether for benchmarking drug dosages (Figure 9b). The most frequently used designation was $\mathrm{mg} / \mathrm{m}^{2}(70.0 \%)$, however, also $\mathrm{mg}(13.0 \%), \mathrm{mg} / \mathrm{m}^{2} / \mathrm{L}$ alone $(4.8 \%)$, or with an added designation in $\mathrm{mg} / \mathrm{m}^{2}(3.9 \%)$ were indicated. Further, concentrations were reported with designations in $\mathrm{mg} / \mathrm{L}(3.9 \%)$. Uncommonly, $\mathrm{mg} / \mathrm{kg}(0.5 \%)$ [49] was used, whereas in in $3.9 \%$ of publications drug dosage was left completely unspecified $[60,71,74,86-88]$. In contrast, concomitant simultaneous i.v. chemotherapy (used for bidirectional HIPEC protocols) was consistently benchmarked in $\mathrm{mg} / \mathrm{m}^{2}$ (Table S9) $[32,33,35,54,65,75,76,81,82,91,108,111,124,127-129,131-133,135-138,140-142,144,145,148,149]$.

\subsection{Carrier Solutions and Diluent Quantities}

A crucial factor potentially influencing the cytotoxicity of HIPEC perfusates is the volume of liquid used for drug dilution, since this is a substantial factor affecting the final drug concentration attainable during HIPEC (Figures 5 and 7). We assessed all HIPEC protocols (assigning minimum and maximum amounts in all cases where a range was reported), which produced 191 values. In $30.4 \%$ of cases no diluent volumes were disclosed. In the remainder, usually diluent volumes were specified in $\mathrm{L}(50.3 \%)$ or else in $\mathrm{L} / \mathrm{m}^{2}$ (18.3\%) (Figure 9c). Frequently, diluent volumes of $3.0 \mathrm{~L}$ or else $2.0 \mathrm{~L} / \mathrm{m}^{2}$ were employed for abdominal perfusion $[78,132]$. In the cases that reported a diluent volume in $\mathrm{L}$, most ranged between $2.0 \mathrm{~L}$ and $6.0 \mathrm{~L}[47,59]$. However, there were also some outliers that report using $0.5 \mathrm{~L}[55,127]$ or increased amounts of 10-12 L [114,119,126], which includes filling a reservoir outside of the patient in the latter and in the former very likely the volume the drug was initially solved in. When using $\mathrm{L} / \mathrm{m}^{2}$ as a benchmark, particularly $2.0 \mathrm{~L} / \mathrm{m}^{2}$ were used, predominantly in L-OHP-based HIPEC protocols, with a few outliers reporting $3.5 \mathrm{~L} / \mathrm{m}^{2}[42,43]$, not influencing resulting maximum attainable drug concentrations due to dosing in $\mathrm{mg} / \mathrm{L}$.

Diluent characteristics, used as a matrix for cytotoxic drugs in the peritoneal cavity, were undisclosed in a substantial fraction of reports (39\%). In $26 \%$ of protocols a dextrose containing solution, a dedicated peritoneal dialysis solution (PDS; $21 \%$ ) or a crystalloid solution (13\%) was employed (Figure 10a). Accounting for different drugs, reporting appeared unequal, since in L-OHP containing protocols information on diluent characteristics was omitted in only $20 \%$ of protocols (Figure 10b) [28,72,75,81,82,91,116,130,143,147], predominantly employing dextrose-based solutions (65\%) [31-35,54,55,66,76,83,108,111,127-129,131-138,140,141,144,145,148-150], whereas in MMC-based HIPEC, in 50\% of protocols respective information was lacking (Figure 10c) $[9,22,24,28,30,34,36,40-$ $45,48-51,54,61-64,66,70-76,81,82,84,85,89,91,93,99,100,104-106,108-114,117,118,123]$. When disclosed in the latter, predominantly PDS (28\%) was mentioned as a diluent $[2,21,23,26,27,29,31-33,37,47,52$, $53,55,56,60,65,68,69,77,86-88,90,94-96,98,101,122,124]$. With a few exceptions, volumes used during HIPEC range in tight physical limits, probably owed to the defined space of the abdominal cavity, when technical issues did not distort the picture, explaining these outliers (Figure 11). 
a

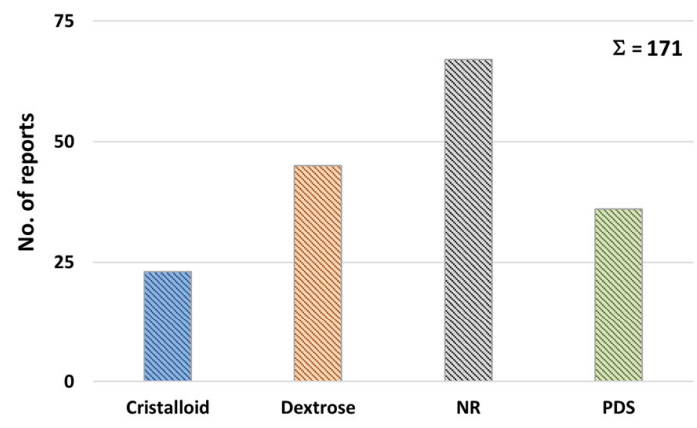

b

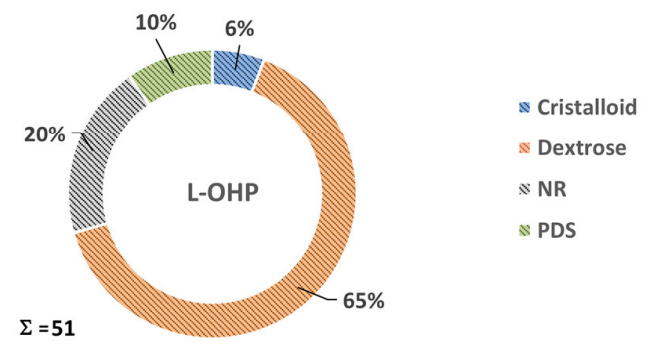

c

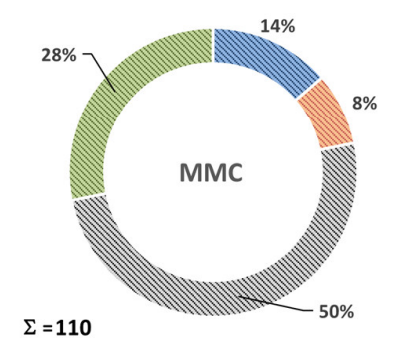

Figure 10. Overview of drug diluents: (a) Bar chart of records reporting the use of crystalloid, dextrose and peritoneal dialysis solutions during HIPEC or else with lacking information (NR). Detailed information on perfusion solutions is available in Tables S1-S8. (b) Percentages of records among L-OHP single-agent or combination treatments. (c) Percentages of records among MMC single-agent or combination treatments. Abbreviations used: L-OHP (oxaliplatin); MMC (mitomycin c); PDS (peritoneal dialysis solution); and NR (not reported).

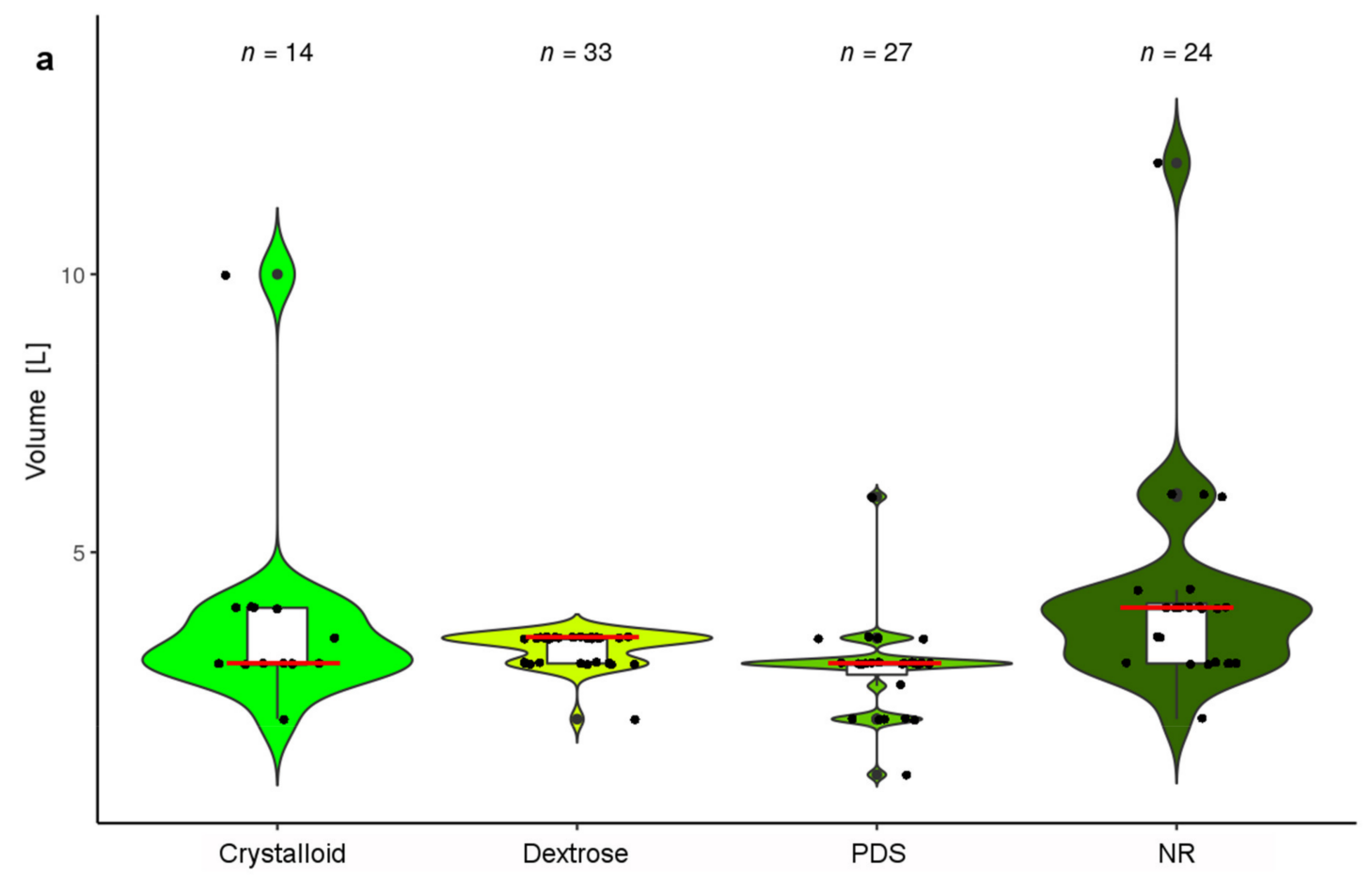

Figure 11. Cont. 


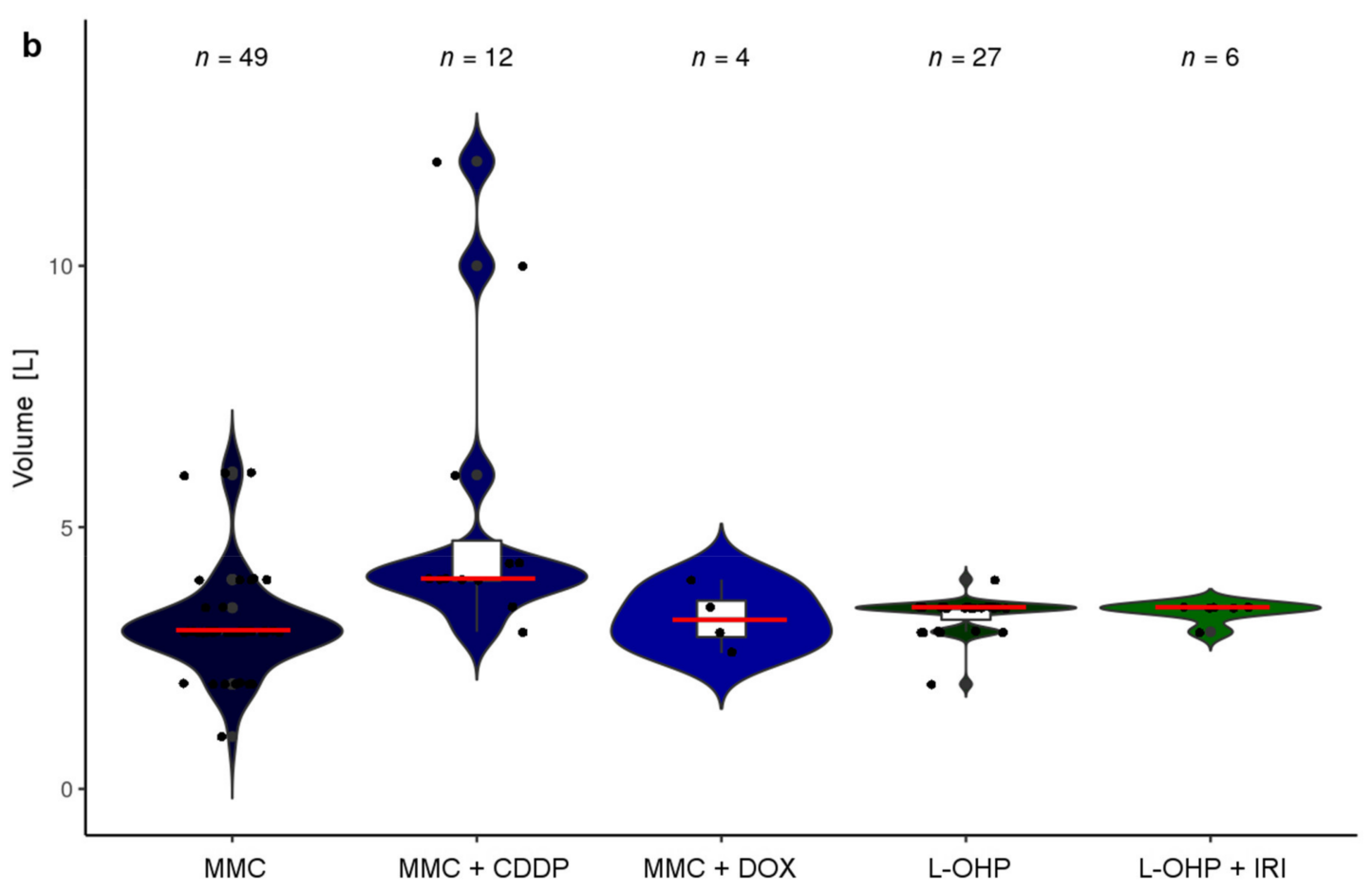

Figure 11. Overview on drug diluent volumes: The violin plots depict volumes of solutions used to dilute drugs employed for HIPEC with protocols categorized according to (a) solvent characteristics or (b) drugs used for HIPEC (reported volumes of $\leq 0.5 \mathrm{~L}$ were omitted). (Median volumes (L): crystalloid: 3.0; Dextrose: 3.5; PDS: 3.0; NR: 4.0/MMC: 3.0; MMC + CDDP: 4.0; MMC + DOX: 3.2; L-OHP: 3.5; and L-OHP + IRI: 3.5). The red bars mark medians and white boxes interquartile range. Abbreviations used: CDDP (cisplatin); DOX (doxorubicin); IRI (irinotecan); MMC (mitomycin c); PDS (peritoneal dialysis solution); L-OHP (oxaliplatin); and NR (not reported).

\subsection{HIPEC Protocols Describing the Use of an Open and Closed Technique}

A further varying factor is the practice of performing HIPEC in a closed or open abdominal cavity (also called coliseum technique) $[155,156]$. Each procedure has their respective set of advantages and disadvantages, the latter for instance allowing manipulation during the procedure, whereas the closed technique may entail less drug exposure of the personnel [156]. Further diverse technical solutions of combining a closed circuit with the option of manipulation during drug perfusion have been suggested $[157,158]$. It has been assumed that there might be an influence of those technical aspects on the outcome of the procedure, but this has never been clinically proven $[156,159]$. Some HIPEC protocols even entail changes in drug dosage, accounting for the open or closed technique used [7]. We therefore assessed all the included reports of HIPEC $(n=171)$, considering whether the open $(44 \%)$ or closed (25\%) technique was performed. The remainder of publications entailed mainly cases, where the used technique was not reported, but also comprised a choice according to surgeons' preference or further technical variations. The differences in fluid volumes used for dilution of drugs, when categorizing the HIPEC protocols according to the three mentioned categories previously mentioned, were rather low and varied between 3.0 L and 3.5 L in median (Figure 12a). However, for the open technique, some outliers were observed that had already been observed previously (Figure 11). This situation therefore also resulted in relatively limited fluctuations in drug dosage, particularly for L-OHP (Figure 12b), where median drug concentrations alternated between about $200 \mu \mathrm{g} / \mathrm{mL}$ and $230 \mu \mathrm{g} / \mathrm{mL}$.

The same holds true for MMC (Figure 12c), where median drug concentrations alternated between $7.2 \mu \mathrm{g} / \mathrm{mL}$ for open HIPEC and $10 \mu \mathrm{g} / \mathrm{mL}$ for both the closed technique and the undetermined category. Hence, here drug concentrations resulted marginally lower in open HIPEC than with the closed technique. Overall, unexpectedly, the effects on drug concentrations remained rather limited, when accounting for open or closed HIPEC technique. 


\section{.}
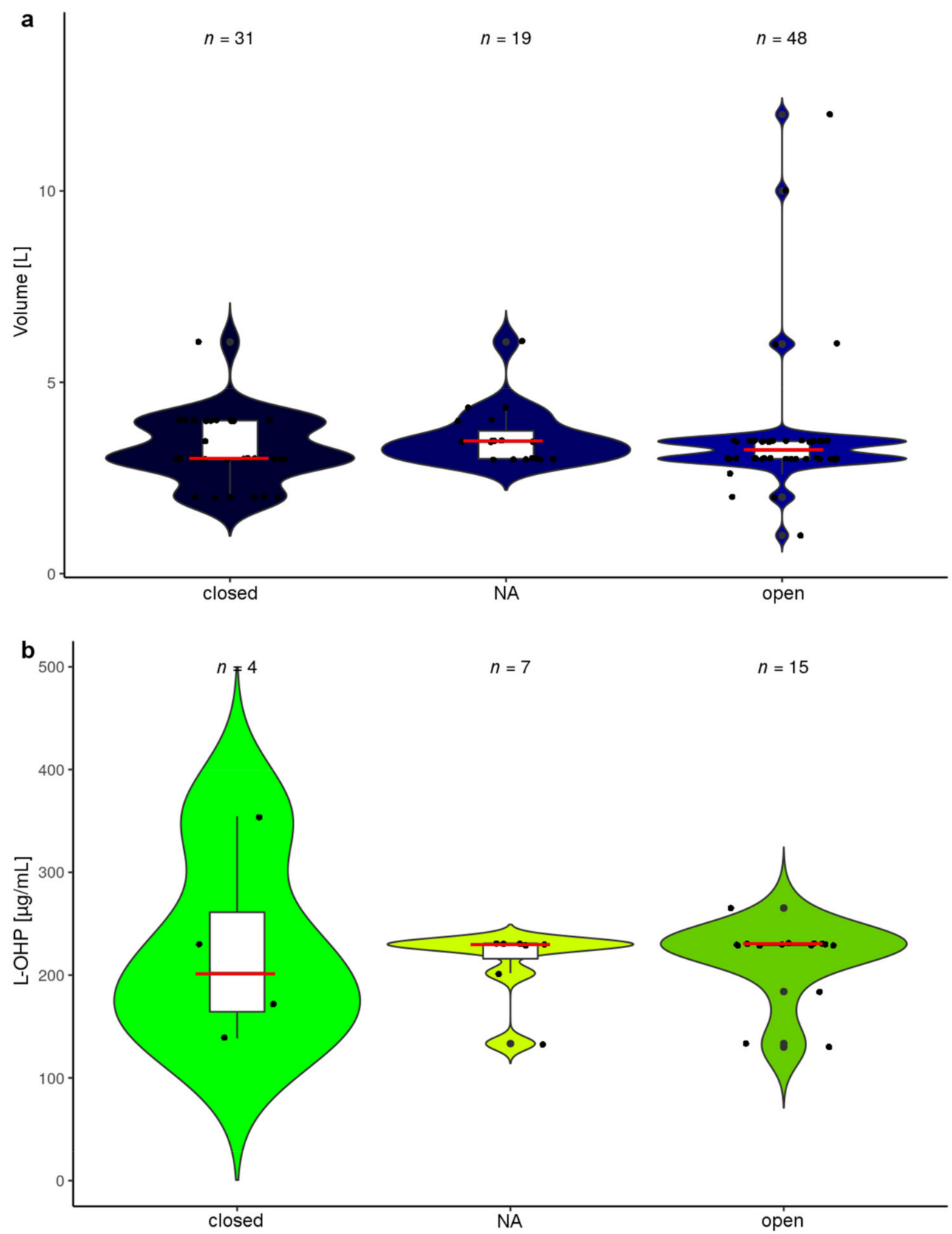

Figure 12. Cont. 


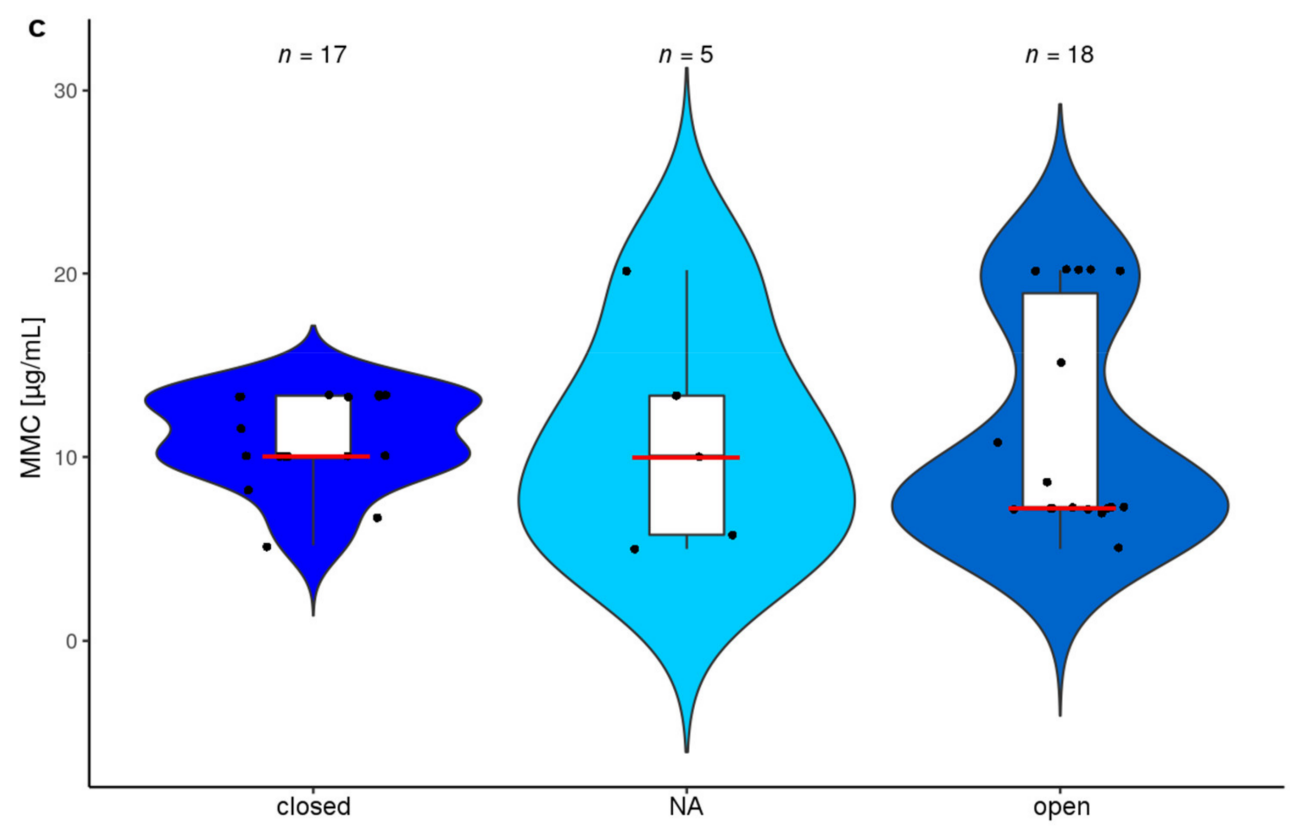

Figure 12. Overview on drug diluent volumes and drug concentrations for L-OHP and MMC according to open and closed HIPEC technique: The violin plots depict protocols categorized according to open/closed or missing/ambiguous information (NA), reporting (a) volumes of solutions used to dilute drugs employed for HIPEC (Median volumes (L): open: 3.2; closed: 3.0; NA: 3.5) or (b) the resulting concentrations of L-OHP (Median drug concentrations $(\mu \mathrm{g} / \mathrm{mL})$ : open: 230; closed: 202; NA: 230 ) and (c) MMC (Median drug concentrations ( $\mu \mathrm{g} / \mathrm{mL}$ ): open: 7.2; closed: 10; NA: 10). Since there is lacking uniformity and for comparative reasons, we imputed data to a presumed average patient (with characteristics of $1.7 \mathrm{~m}$ height, $70 \mathrm{~kg}$ weight and $1.73 \mathrm{~m}^{2}$ body surface area). Further, in case of ambiguity values were maximized using the maximal drug amounts and the minimum volumes reported. The red bars mark medians and white boxes interquartile range. Protocols with missing data or reporting $\leq 4$ patients and the outlier [121] were omitted. Abbreviations used: L-OHP (oxaliplatin); MMC (mitomycin c); NA (not assigned).

3.12. HIPEC Protocols Entailing Simultaneous Intravenous and Intraperitoneal (Bidirectional) Drug Administration and Early Postoperative Intraperitoneal Chemotherapy (EPIC)

Simultaneous application of cytotoxic drugs both intravenously and to the peritoneum was first reported in 2002 [131] and has been described in 29 publications thereafter (Table S9) [32,33,35,54, $65,75,76,81,82,91,108,111,124,127-129,132,133,135-138,140-142,144,145,148,149]$. In CRC, all respective approaches used L-OHP-based HIPEC, either as a monotherapy or combined with DOX or IRI. The drugs administered by i.v. route in these cases were 5-FU \pm Leucovorin without exception. The reason for this practice may be assumed in the lacking efficiency of L-OHP as a monotherapy [160], however this practice does not necessarily seem congruent, when assuming the frequently advocated theory of a peritoneum plasma barrier [4], which is a fundamental assumption for intraperitoneal drug administration.

Considering the use of EPIC after HIPEC, this was predominantly practiced together with MMC-based HIPEC protocols using 5-FU. Nevertheless, also combinations with L-OHP [28,55,60,127,140] and L-OHP + IRI [140] as well as MMC + CDDP [42] were reported.

\subsection{Hyperthermia}

Since hyperthermia is a defining feature of HIPEC, temperatures used were unanimously reported above physiological levels of $37^{\circ} \mathrm{C}$. It has to be noted that many different techniques and approaches were used to measure temperatures, impairing their comparability. For instance, there are publications where inflow temperatures amount to up to $48^{\circ} \mathrm{C}$ [48], whereas in other publications, temperatures in 
the abdomen were reported ranging from $38.5^{\circ} \mathrm{C}$ [79] to $44^{\circ} \mathrm{C}$ [73]. Most frequently target temperatures were reported at $42.0^{\circ} \mathrm{C}$, but often a temperature range was given (Figure 13).
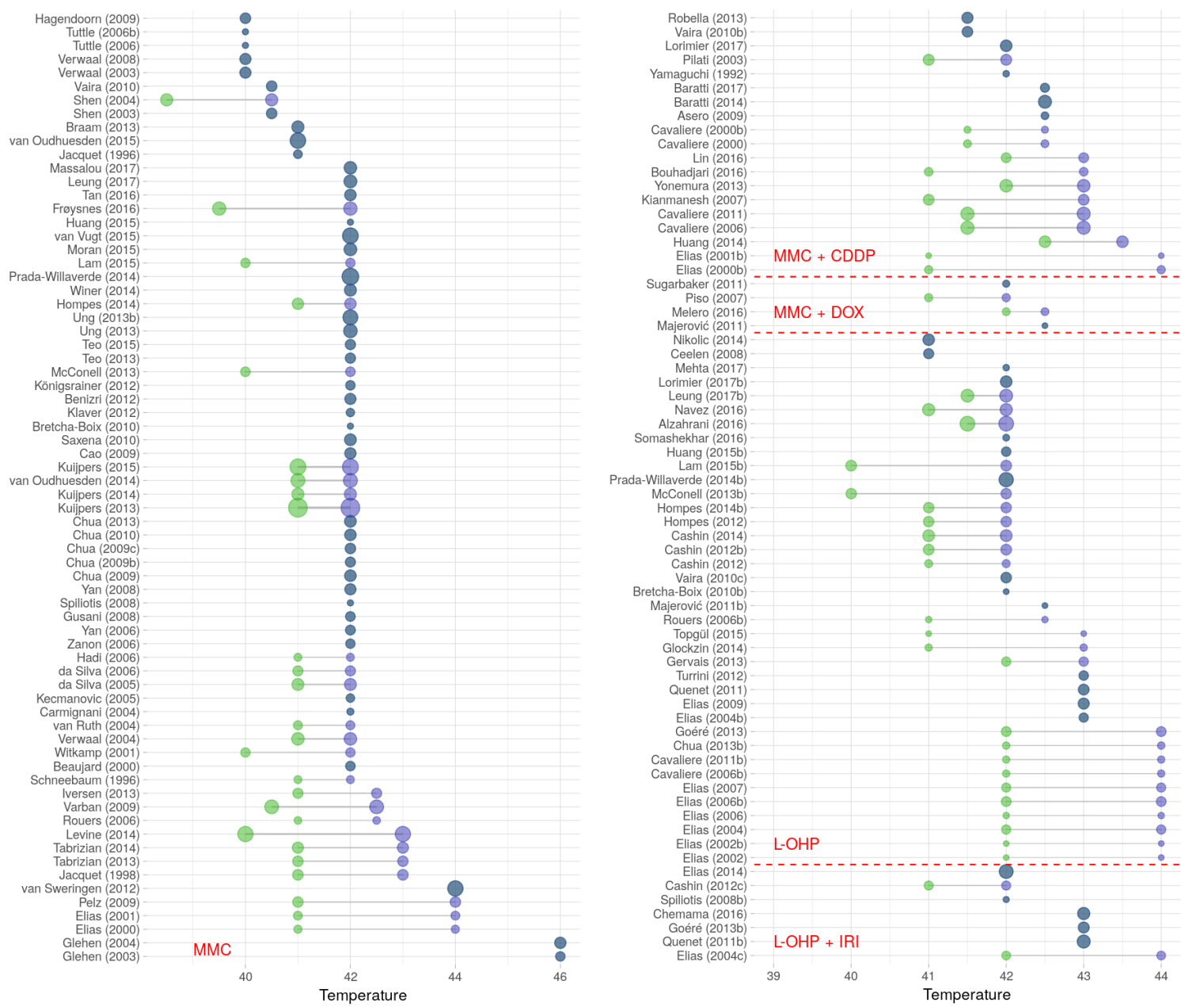

Figure 13. Temperatures during HIPEC: The Lollipop plot depicts temperatures (in ${ }^{\circ} \mathrm{C}$ ) reported for HIPEC protocols described in the literature (only reports with $n>4$ patients and protocols containing MMC or L-OHP single drug or in combinations were included; temperatures $\geq 46{ }^{\circ} \mathrm{C}$ were assigned $46^{\circ} \mathrm{C}$ ). Green dots signify minimum temperature and purple dots maximum temperatures in case a range was reported. Symbols are lg scaled according to number of patients included. Publications conform to annotations given in Tables S1-S5, with Arabic letters marking chronological order (if required). Abbreviations used: CDDP (cisplatin); DOX (doxorubicin); IRI (irinotecan); L-OHP (oxaliplatin); and MMC (mitomycin c).

\section{Discussion}

This comprehensive review on HIPEC conduct in peritoneal metastases (PM) from colorectal cancer (CRC) adds tangible evidence to the notion of heterogeneity and lacking uniformity in perioperative intraperitoneal drug administration [9,12,161]. We identified at least 60 different HIPEC protocols regarding different drugs used and their concentrations among 171 reports about HIPEC conduct, mentioned in 135 publications and included in this systematic review. Since relevant information was frequently lacking, those accounts may rather underestimate the true heterogeneity. Surprisingly, there was also uniformity within subareas, as evidenced with L-OHP use. On the downside, frequently HIPEC procedures are only vaguely described, omitting relevant information and focusing on other aspects of the procedure. This factor may even contribute to unintentional 
arbitrariness in subsequent research conduct and patient treatment, when aiming to reproduce protocols described in the literature.

A cursory examination already revealed that drug use has been inconsistent and included many different cytotoxic agents, foremost MMC and L-OHP, which are established to exert synergistic effects with heat, potentially a crucial factor for their choice in the first place [162]. MMC was the most commonly used drug in HIPEC, which was also found by a recent international survey [163], followed by L-OHP, both for single-agent use and drug combinations. Even though monotherapies prevail for HIPEC, there is a variety of drug combinations, comprising one fifth of the evaluated protocols, while for $\mathrm{CRC}$ the choice of the most suitable drug or drug combination remains currently unsettled. The first protocol established by RCT and therefore best evidence for many years used MMC [2], but tested CRS and HIPEC vs. palliative chemotherapy. Recent RCT results in CRC failed to show an improved survival, when assessing the survival benefit added by HIPEC with L-OHP $\left(460 \mathrm{mg} / \mathrm{m}^{2}\right.$ for $30 \mathrm{~min}$ in the PRODIGE 7 trial (NCT00769405)) [6,7]. Therefore, whereas surgery resulted in impressively improved survival, the role of HIPEC generally remains heavily disputed [164]. On the other side, current RCT data are available for ovarian cancer, establishing a survival benefit for HIPEC with CDDP (100 $\mathrm{mg} / \mathrm{m}^{2}$ for $60 \mathrm{~min}$ in patients responsive to carboplatin/paclitaxel) [8].

These very topical results underscore the need to critically reassess HIPEC and its conduct, supporting the notion that a systematic overview of the status quo is a valuable attempt to complete the picture, providing further evidence in addition to consensus statements, and global surveys on this topic already published $[155,163]$.

Against this background, a highly relevant aspect is the cytotoxic profile of drugs used, which is very difficult to control even when disregarding potential drug interactions and applying single drugs only, since the diluent itself may already influence drug effects (i.e., the matrix/ carrier solution drugs are diluted in for peritoneal perfusion). Further drug properties matter, for example with IRI, which needs to be enzymatically biotransformed for activation [165]. This step may certainly take place in malignant cells, but it is neither established whether an exposure time of $30 \mathrm{~min}$ for HIPEC with IRI would suffice for the activation nor if similar pharmacokinetics for i.v. and i.p. application can be assumed [166]. Therefore, the application of HCPT, an active metabolite of IRI, seems consequential [126].

Beyond this, for a long-time L-OHP has been administered with glucose containing solutions only, based on the understanding that the drug remains stable under such conditions [167]. However, since L-OHP probably requires transformation to gain cytotoxic properties, chloride containing solutions promoting activation may even be more advantageous. Unfortunately, many active metabolites of L-OHP and their kinetics are hardly evaluated thus far [168]. Therefore, respective investigations clarifying under which conditions drug bioactivity is optimal appear crucial $[167,168]$. According to our overview, a combination of glucose-based solutions with L-OHP (65\%) generally prevailed, but also chloride-containing solutions have been employed [121,139]. Interestingly with MMC containing HIPEC protocols, respective information was much more frequently provided.

Additional heterogeneity is introduced in protocols that partition drug administrations into multiple fractionated applications during HIPEC or apply sex-adapted regimens [30,50,59]. It is an interesting fact that both practices are common with $\mathrm{MMC}$, whereas for other drugs or drug combinations this was never observed by us.

Generally, drug dosing seems a particularly complex and error-prone aspect in HIPEC, as drug amounts are usually reported either as drug amount (in $\mathrm{mg}$ ) or amount per $\mathrm{m}^{2}$ (body surface area) and at times as concentrations administered in $\mathrm{mg}$ per L adapted to the body surface area $\left(\mathrm{m}^{2}\right)$. Accordingly, HIPEC protocols are not (easily) comparable, not even on a quantitative level, regardless of any other factors. Only very few reports exist, where a drug concentration in $\mathrm{mg} / \mathrm{L}$ is indicated, which is particularly the case for early publications on HIPEC with MMC [22,42,43,47,48,57,58,78]. To cope with this, we assumed a virtual average patient enabling comparisons and providing drug concentrations employed for HIPEC, which may aid in establishing the status quo. Such knowledge is particularly 
relevant and will be required for any attempts of modeling HIPEC. Based on our survey, we may advice caution with regard to dosing drugs, since we witnessed a statement that HIPEC was performed with $460 \mathrm{mg} / \mathrm{m}^{2} / \mathrm{L} \mathrm{L-OHP} \mathrm{[121],} \mathrm{accounting} \mathrm{for} \mathrm{a} \mathrm{substantially} \mathrm{increased} \mathrm{final} \mathrm{drug} \mathrm{concentration}$ compared to previous work [131]. Giving these authors the benefit of a doubt by assuming that there was a mistake and $460 \mathrm{mg} / \mathrm{m}^{2}$ was meant instead, the drug concentration (about $200 \mu \mathrm{g} / \mathrm{mL} \mathrm{L-OHP)}$ would result similar to most other protocols. A clear sign for subjectivity in HIPEC conduct was mentioned in a report from 2011, where investigators frankly admitted that either MMC or L-OHP were chosen "according to surgeon's preference" [169], which may be supposed for handling other aspects of HIPEC as well, since basic research and firm evidence is frequently missing.

Frequently, the procedure is not restricted to HIPEC only but also features concomitant intravenous drug application. This approach of (simultaneous) bidirectional treatment has been theoretically supported by the hypothesis that long-term survival may be improved in patients with higher systemic drug levels [162]. To our knowledge, however, there is no convincing evidence so far supporting concomitant i.v. drug administration during HIPEC [170]. Of note, according to our data, this practice is restricted to L-OHP single-agent or combination HIPEC treatments together with i.v. 5-FU + / - leucovorin. Speculatively, more complex therapy regimens may result more error prone and even entail an increased morbidity risk.

Another observation is that the volumes used for dilution of HIPEC drugs vary substantially from $0.5 \mathrm{~L}$ to $12 \mathrm{~L}$. Of course, the latter does not refer to the volumes applied to the abdomen but rather a water bath used for heating [126] and the former speculatively refers to the volume the drug was initially solved in. Nevertheless, respective practices can influence final drug concentrations substantially. Interestingly, the practice of performing open and closed HIPEC procedures affected the resulting median drug concentrations only slightly, due to comparable volumes used for diluting drugs in both groups. We concur with preceding authors that reporting definite concentrations of drugs employed during HIPEC should be best practice and a standard measure is urgently needed to introduce comparability in this regard [171].

Further aspects complicate the picture, namely exposure times of peritoneal surfaces to respective drugs and hyperthermia. Whereas there are natural limits to applying heat to the peritoneum, restricted to a window of about $7{ }^{\circ} \mathrm{C}$ between $37^{\circ} \mathrm{C}$ and $44^{\circ} \mathrm{C}$, the duration of HIPEC seems limited by practical aspects such as additional costs of prolonged procedures and missing evidence for the time needed. The rationale for using hyperthermia is based on basic research and is theoretically plausible, as for instance $40^{\circ} \mathrm{C}$ has been proposed as a critical threshold in vitro [172], while resulting clinical effects ultimately remain unproven [162]. Against this background, it seems quite surprising to us that with MMC predominantly 90 min exposure was chosen, whereas the duration for L-OHP was mainly restricted to only $30 \mathrm{~min}$.

\section{Conclusions}

Our literature survey provides a comprehensive systematic overview of about 35 years of clinical experience in HIPEC (1981-2016), reported in scientific articles published between 1992 and 2017. Since current RCT findings have raised critical questions that need to be addressed, it seems sensible to revisit HIPEC conduct in CRC comprehensively. As HIPEC is associated with specific risks that would otherwise be negligible, including spontaneous bowel perforations $[173,174]$ or electrolyte imbalances due to using dextrose-based perfusion solutions as a matrix [175], as well as considerably increased rates of acute renal impairment and bleeding complications in platinum-based HIPEC, respectively, critical questions must be addressed [176]. Based on our survey, HIPEC does not appear as a single treatment, but as an array thereof with many identifiable specific, potentially critical aspects that warrant critical assessment.

The fact that clear standards in reporting HIPEC conduct are lacking prevents definite comparisons between published protocols and hinders a comprehensive assessment of data. The introduction of standardized reporting for HIPEC drug dosage using concentrations instead of being defined by 
body surface area has been requested on pharmacological grounds for many years [171], and we may provide a status quo here, necessary for basic research and modeling. However, attempts at standardizing HIPEC ad libitum, without sufficient scientific evidence seem misleading to us and may suggest false security, whereas the general concept is laudable $[11,142]$. We agree that the introduction of standards may reduce the margin of error and promote routines, thereby increasing patient security, as proven in the past [9]. Nevertheless, we frequently missed crucial information on many aspects of HIPEC, therefore efforts implementing standards in reporting HIPEC procedures are critical to reach better comparability.

Supplementary Materials: The following supplementary material is available online at http:/ /www.mdpi.com/ 2077-0383/7/12/567/s1, Table S1: Original data MMC HIPEC protocols, Table S2: Original data MMC + CDDP HIPEC protocols; Table S3: Original data MMC + DOX HIPEC protocols, Table S4: Original data L-OHP HIPEC protocols, Table S5: Original data L-OHP + IRI HIPEC protocols, Table S6: Original data CDDP HIPEC protocols, Table S7: Original data HIPEC protocols with rare drug combinations, Table S8: Original data HIPEC protocols with rare monotherapies, Table S9: Original data concomitant i.v. chemotherapy during HIPEC; Table S10: PRISMA checklist.

Author Contributions: Conceptualization: M.W.L. and S.B.; literature survey: C.Y. and G.H.; data compilation: C.Y. and G.H.; methodology: G.H., A.T. and M.W.L.; software: A.T.; validation: C.Y., A.T. and M.W.L.; formal analysis: A.T. S.P.H. and M.W.L.; investigation: C.Y., A.T., S.P.H., S.B. and M.W.L.; resources: M.S., I.K. and A.K.; data curation: C.Y., G.H., A.T. and M.W.L; writing-original draft preparation: C.Y. and M.W.L; writing-review and editing: S.P.H.; M.S., I.K., A.K., S.B., and M.W.L; visualization: G.H.; A.T. S.P.H. and M.W.L; supervision: M.S.; A.K., S.B. and M.W.L.; project administration: C.Y., I.K. and M.W.L.; funding acquisition: M.S. and A.K. All authors approved the final version of the manuscript.

Funding: This work was supported by the Robert Bosch Stiftung, Stuttgart, Germany and the Deutsche Krebshilfe (Grant No: 70112564) to Matthias Schwab. We acknowledge support by Deutsche Forschungsgemeinschaft (DFG) and Open Access Publishing Fund of University of Tübingen.

Acknowledgments: This work was not preregistered and a formal registration and systematic review protocol omitted. A PRISMA checklist (http:/ / prisma-statement.org) is provided as Table S10.

Conflicts of Interest: M.W.L. and A.K. have received a research grant by RanD S.r.l., a manufacturer of devices and consumables for HIPEC, unrelated to the present work. The other authors declare no potential conflicts of interest.

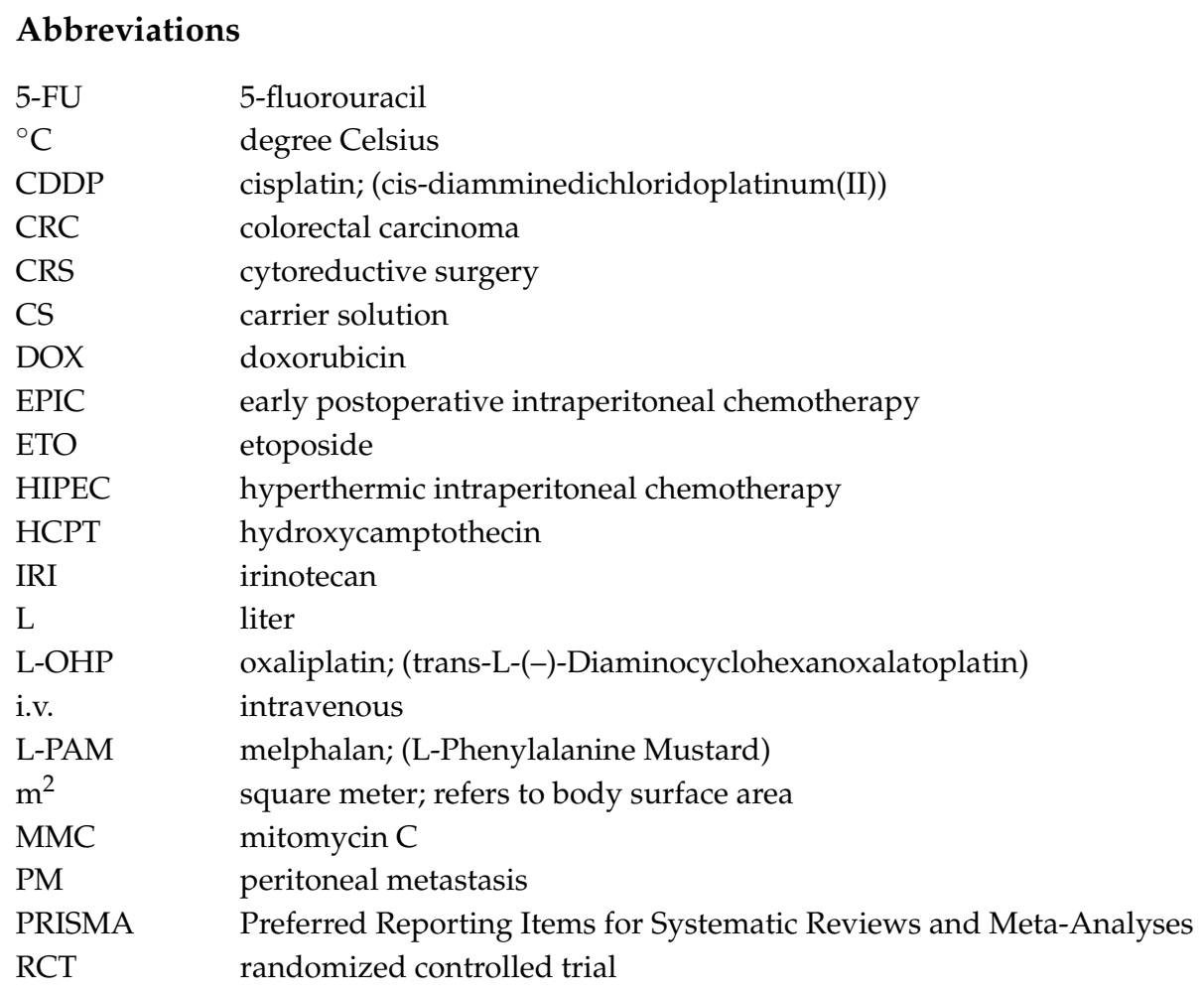




\section{References}

1. Lambert, L.A. Looking up: Recent advances in understanding and treating peritoneal carcinomatosis. CA Cancer J. Clin. 2015, 65, 284-298. [CrossRef] [PubMed]

2. Verwaal, V.J.; van Ruth, S.; de Bree, E.; van Sloothen, G.W.; van Tinteren, H.; Boot, H.; Zoetmulder, F.A. Randomized trial of cytoreduction and hyperthermic intraperitoneal chemotherapy versus systemic chemotherapy and palliative surgery in patients with peritoneal carcinomatosis of colorectal cancer. J. Clin. Oncol. 2003, 21, 3737-3743. [CrossRef] [PubMed]

3. Sugarbaker, P.H. Surgical treatment of peritoneal carcinomatosis: 1988 Du Pont lecture. Can. J. Surg. 1989, 32, 164-170.

4. Jacquet, P.; Sugarbaker, P.H. Peritoneal-plasma barrier. Cancer Treat. Res. 1996, 82, 53-63.

5. Ceelen, W.P.; Pahlman, L.; Mahteme, H. Pharmacodynamic aspects of intraperitoneal cytotoxic therapy. Cancer Treat. Res. 2007, 134, 195-214.

6. Esquivel, J. Cytoreductive surgery and hyperthermic intraperitoneal chemotherapy for colorectal cancer: Survival outcomes and patient selection. J. Gastrointest. Oncol. 2016, 7, 72-78. [PubMed]

7. Ceelen, W. HIPEC with oxaliplatin for colorectal peritoneal metastasis: The end of the road? Eur. J. Surg. Oncol. 2018. [CrossRef] [PubMed]

8. Van Driel, W.J.; Koole, S.N.; Sikorska, K.; Schagen van Leeuwen, J.H.; Schreuder, H.W.R.; Hermans, R.H.M.; de Hingh, I.H.J.T.; van der Velden, J.; Arts, H.J.; Massuger, L.F.A.G.; et al. Hyperthermic Intraperitoneal Chemotherapy in Ovarian Cancer. N. Engl. J. Med. 2018, 378, 230-240. [CrossRef]

9. Kuijpers, A.M.; Aalbers, A.G.; Nienhuijs, S.W.; de Hingh, I.H.; Wiezer, M.J.; van Ramshorst, B.; van Ginkel, R.J.; Havenga, K.; Heemsbergen, W.D.; Hauptmann, M.; et al. Implementation of a standardized HIPEC protocol improves outcome for peritoneal malignancy. World J. Surg. 2015, 39, 453-460. [CrossRef]

10. Lemoine, L.; Sugarbaker, P.; Van der Speeten, K. Drugs, doses, and durations of intraperitoneal chemotherapy: Standardising HIPEC and EPIC for colorectal, appendiceal, gastric, ovarian peritoneal surface malignancies and peritoneal mesothelioma. Int. J. Hyperth. 2017, 33, 582-592. [CrossRef]

11. Li, Y.; Zhou, Y.F.; Liang, H.; Wang, H.Q.; Hao, J.H.; Zhu, Z.G.; Wan, D.S.; Qin, L.X.; Cui, S.Z.; Ji, J.F.; et al. Chinese expert consensus on cytoreductive surgery and hyperthermic intraperitoneal chemotherapy for peritoneal malignancies. World J. Gastroenterol. 2016, 22, 6906-6916. [CrossRef] [PubMed]

12. Turaga, K.; Levine, E.; Barone, R.; Sticca, R.; Petrelli, N.; Lambert, L.; Nash, G.; Morse, M.; Adbel-Misih, R.; Alexander, H.R.; et al. Consensus guidelines from The American Society of Peritoneal Surface Malignancies on standardizing the delivery of hyperthermic intraperitoneal chemotherapy (HIPEC) in colorectal cancer patients in the United States. Ann. Surg. Oncol. 2014, 21, 1501-1505. [CrossRef] [PubMed]

13. R Core Team. R: A Language and Environment for Statistical Computing. R Foundation for Statistical Computing Vienna, Austria. 2018. Available online: http:/ /www.R-project.org/ (accessed on 2 November 2018).

14. Wickham, H.; Françoise, R.; Henry, L.; Müller, K. dplyr (R-package). The Comprehensive R Archive Network. 2018. Available online: https:/ /CRAN.R-project.org/package=dplyr (accessed on 2 November 2018).

15. Wickham, H. Ggplot2: Elegant Graphics for Data Analysis, 2nd ed.; Gentleman, R., Hornik, K., Parmigiani, G., Eds.; Springer: New York, NY, USA, 2009. Available online: https:/ /CRAN.R-project.org/package=ggplot2 (accessed on 2 November 2018).

16. Wickham, H. tidyverse (R-package). The Comprehensive R Archive Network. 2018. Available online: https: / CRAN.R-project.org/package=tidyverse (accessed on 2 November 2018).

17. Wickham, H. The Split-Apply-Combine Strategy for Data Analysis. J. Stat. Softw. 2011, 40, 29. Available online: https: / /CRAN.R-project.org/package=plyr (accessed on 2 November 2018). [CrossRef]

18. Kassambara, A. ggpubr (R-package). The Comprehensive R Archive Network. 2018. Available online: https: / /CRAN.R-project.org/package=ggpubr (accessed on 2 November 2018).

19. Liberati, A.; Altman, D.G.; Tetzlaff, J.; Mulrow, C.; Gøtzsche, P.C.; Ioannidis, J.P.; Clarke, M.; Devereaux, P.J.; Kleijnen, J.; Moher, D. The PRISMA statement for reporting systematic reviews and meta-analyses of studies that evaluate health care interventions: Explanation and elaboration. PLoS Med. 2009, 6, e1000100. [CrossRef]

20. Moher, D.; Liberati, A.; Tetzlaff, J.; Altman, D.G.; Group, P. Preferred reporting items for systematic reviews and meta-analyses: The PRISMA statement. PLoS Med. 2009, 6, e1000097. [CrossRef] [PubMed] 
21. Witkamp, A.J.; de Bree, E.; Kaag, M.M.; Boot, H.; Beijnen, J.H.; van Slooten, G.W.; van Coevorden, F.; Zoetmulder, F.A. Extensive cytoreductive surgery followed by intra-operative hyperthermic intraperitoneal chemotherapy with mitomycin-C in patients with peritoneal carcinomatosis of colorectal origin. Eur. J. Cancer 2001, 37, 979-984. [CrossRef]

22. Beaujard, A.C.; Glehen, O.; Caillot, J.L.; Francois, Y.; Bienvenu, J.; Panteix, G.; Garbit, F.; Grandclément, E.; Vignal, J.; Gilly, F.N. Intraperitoneal chemohyperthermia with mitomycin C for digestive tract cancer patients with peritoneal carcinomatosis. Cancer 2000, 88, 2512-2519. [CrossRef]

23. Benizri, E.I.; Bernard, J.L.; Rahili, A.; Benchimol, D.; Bereder, J.M. Small bowel involvement is a prognostic factor in colorectal carcinomatosis treated with complete cytoreductive surgery plus hyperthermic intraperitoneal chemotherapy. World J. Surg. Oncol. 2012, 10, 56. [CrossRef] [PubMed]

24. Bijelic, L.; Yan, T.D.; Sugarbaker, P.H. Failure analysis of recurrent disease following complete cytoreduction and perioperative intraperitoneal chemotherapy in patients with peritoneal carcinomatosis from colorectal cancer. Ann. Surg. Oncol. 2007, 14, 2281-2288. [CrossRef]

25. Bijelic, L.; Yan, T.D.; Sugarbaker, P.H. Treatment failure following complete cytoreductive surgery and perioperative intraperitoneal chemotherapy for peritoneal dissemination from colorectal or appendiceal mucinous neoplasms. J. Surg. Oncol. 2008, 98, 295-299. [CrossRef]

26. Boutros, C.; Somasundar, P.; Espat, N.J. Early results on the use of biomaterials as adjuvant to abdominal wall closure following cytoreduction and hyperthermic intraperitoneal chemotherapy. World J. Surg. Oncol. 2010, 8, 72. [CrossRef]

27. Braam, H.J.; Boerma, D.; Wiezer, M.J.; van Ramshorst, B. Hyperthermic intraperitoneal chemotherapy during primary tumour resection limits extent of bowel resection compared to two-stage treatment. Eur. J. Surg. Oncol. 2013, 39, 988-993. [CrossRef]

28. Bretcha-Boix, P.; Farre-Alegre, J.; Sureda, M.; Dussan, C.; Perez Ruixo, J.J.; Brugarolas Masllorens, A. Cytoreductive surgery and perioperative intraperitoneal chemotherapy in patients with peritoneal carcinomatosis of colonic origin: Outcomes after 7 years' experience of a new centre for peritoneal surface malignancies. Clin. Transl. Oncol. 2010, 12, 437-442. [CrossRef]

29. Cao, C.Q.; Yan, T.D.; Liauw, W.; Morris, D.L. Comparison of optimally resected hepatectomy and peritonectomy patients with colorectal cancer metastasis. J. Surg. Oncol. 2009, 100, 529-533. [CrossRef]

30. Carmignani, C.P.; Ortega-Perez, G.; Sugarbaker, P.H. The management of synchronous peritoneal carcinomatosis and hematogenous metastasis from colorectal cancer. Eur. J. Surg. Oncol. 2004, 30, 391-398. [CrossRef] [PubMed]

31. Cashin, P.H.; Dranichnikov, F.; Mahteme, H. Cytoreductive surgery and hyperthermic intra-peritoneal chemotherapy treatment of colorectal peritoneal metastases: Cohort analysis of high volume disease and cure rate. J. Surg. Oncol. 2014, 110, 203-206. [CrossRef]

32. Cashin, P.H.; Graf, W.; Nygren, P.; Mahteme, H. Cytoreductive surgery and intraperitoneal chemotherapy for colorectal peritoneal carcinomatosis: Prognosis and treatment of recurrences in a cohort study. Eur. J. Surg. Oncol. 2012, 38, 509-515. [CrossRef]

33. Cashin, P.H.; Graf, W.; Nygren, P.; Mahteme, H. Intraoperative hyperthermic versus postoperative normothermic intraperitoneal chemotherapy for colonic peritoneal carcinomatosis: A case-control study. Ann. Oncol. 2012, 23, 647-652. [CrossRef]

34. Ceelen, W.; Van Nieuwenhove, Y.; Putte, D.V.; Pattyn, P. Neoadjuvant chemotherapy with bevacizumab may improve outcome after cytoreduction and hyperthermic intraperitoneal chemoperfusion (HIPEC) for colorectal carcinomatosis. Ann. Surg. Oncol. 2014, 21, 3023-3028. [CrossRef] [PubMed]

35. Chua, T.C.; Liauw, W.; Zhao, J.; Morris, D.L. Comparative analysis of perioperative intraperitoneal chemotherapy regimen in appendiceal and colorectal peritoneal carcinomatosis. Int. J. Clin. Oncol. 2013, 18, 439-446. [CrossRef]

36. Chua, T.C.; Morris, D.L.; Esquivel, J. Impact of the peritoneal surface disease severity score on survival in patients with colorectal cancer peritoneal carcinomatosis undergoing complete cytoreduction and hyperthermic intraperitoneal chemotherapy. Ann. Surg. Oncol. 2010, 17, 1330-1336. [CrossRef]

37. Chua, T.C.; Pelz, J.O.; Kerscher, A.; Morris, D.L.; Esquivel, J. Critical analysis of 33 patients with peritoneal carcinomatosis secondary to colorectal and appendiceal signet ring cell carcinoma. Ann. Surg. Oncol. 2009, 16, 2765-2770. [CrossRef] 
38. Chua, T.C.; Yan, T.D.; Ng, K.M.; Zhao, J.; Morris, D.L. Significance of lymph node metastasis in patients with colorectal cancer peritoneal carcinomatosis. World J. Surg. 2009, 33, 1488-1494. [CrossRef]

39. Chua, T.C.; Yan, T.D.; Zhao, J.; Morris, D.L. Peritoneal carcinomatosis and liver metastases from colorectal cancer treated with cytoreductive surgery perioperative intraperitoneal chemotherapy and liver resection. Eur. J. Surg. Oncol. 2009, 35, 1299-1305. [CrossRef]

40. Da Silva, R.G.; Sugarbaker, P.H. Analysis of prognostic factors in seventy patients having a complete cytoreduction plus perioperative intraperitoneal chemotherapy for carcinomatosis from colorectal cancer. J. Am. Coll. Surg. 2006, 203, 878-886. [CrossRef]

41. De Bree, E.; Koops, W.; Kroger, R.; van Ruth, S.; Verwaal, V.J.; Zoetmulder, F.A. Preoperative computed tomography and selection of patients with colorectal peritoneal carcinomatosis for cytoreductive surgery and hyperthermic intraperitoneal chemotherapy. Eur. J. Surg. Oncol. 2006, 32, 65-71. [CrossRef]

42. Elias, D.; Antoun, S.; Goharin, A.; Otmany, A.E.; Puizillout, J.M.; Lasser, P. Research on the best chemohyperthermia technique of treatment of peritoneal carcinomatosis after complete resection. Int. J. Surg. Investig. 2000, 1, 431-439.

43. Elias, D.; Blot, F.; El Otmany, A.; Antoun, S.; Lasser, P.; Boige, V.; Rougier, P.; Ducreux, M. Curative treatment of peritoneal carcinomatosis arising from colorectal cancer by complete resection and intraperitoneal chemotherapy. Cancer 2001, 92, 71-76. [CrossRef]

44. Franko, J.; Gusani, N.J.; Holtzman, M.P.; Ahrendt, S.A.; Jones, H.L.; Zeh, H.J., 3rd; Bartlett, D.L. Multivisceral resection does not affect morbidity and survival after cytoreductive surgery and chemoperfusion for carcinomatosis from colorectal cancer. Ann. Surg. Oncol. 2008, 15, 3065-3072. [CrossRef]

45. Franko, J.; Ibrahim, Z.; Gusani, N.J.; Holtzman, M.P.; Bartlett, D.L.; Zeh, H.J., 3rd. Cytoreductive surgery and hyperthermic intraperitoneal chemoperfusion versus systemic chemotherapy alone for colorectal peritoneal carcinomatosis. Cancer 2010, 116, 3756-3762. [CrossRef]

46. Frøysnes, I.S.; Larsen, S.G.; Spasojevic, M.; Dueland, S.; Flatmark, K. Complete cytoreductive surgery and hyperthermic intraperitoneal chemotherapy for colorectal peritoneal metastasis in Norway: Prognostic factors and oncologic outcome in a national patient cohort. J. Surg. Oncol. 2016, 114, 222-227. [CrossRef] [PubMed]

47. Gilly, F.N.; Carry, P.Y.; Sayag, A.C.; Brachet, A.; Panteix, G.; Salle, B.; Bienvenu, J.; Burgard, G.; Guibert, B.; Banssillon, V. Regional chemotherapy (with mitomycin C) and intra-operative hyperthermia for digestive cancers with peritoneal carcinomatosis. Hepato-Gastroenterol. 1994, 41, 124-129.

48. Glehen, O.; Cotte, E.; Schreiber, V.; Sayag-Beaujard, A.C.; Vignal, J.; Gilly, F.N. Intraperitoneal chemohyperthermia and attempted cytoreductive surgery in patients with peritoneal carcinomatosis of colorectal origin. Br. J. Surg. 2004, 91, 747-754. [CrossRef]

49. Glehen, O.; Mithieux, F.; Osinsky, D.; Beaujard, A.C.; Freyer, G.; Guertsch, P.; Francois, Y.; Peyrat, P.; Panteix, G.; Vignal, J.; et al. Surgery combined with peritonectomy procedures and intraperitoneal chemohyperthermia in abdominal cancers with peritoneal carcinomatosis: A phase II study. J. Clin. Oncol. 2003, 21, 799-806. [CrossRef]

50. Gomes da Silva, R.; Cabanas, J.; Sugarbaker, P.H. Limited survival in the treatment of carcinomatosis from rectal cancer. Dis. Colon Rectum 2005, 48, 2258-2263. [CrossRef]

51. Gusani, N.J.; Cho, S.W.; Colovos, C.; Seo, S.; Franko, J.; Richard, S.D.; Edwards, R.P.; Brown, C.K.; Holtzman, M.P.; Zeh, H.J.; et al. Aggressive surgical management of peritoneal carcinomatosis with low mortality in a high-volume tertiary cancer center. Ann. Surg. Oncol. 2008, 15, 754-763. [CrossRef] [PubMed]

52. Hadi, R.; Saunders, V.; Utkina, O.; Clingan, P.; Kam, P.; Links, M.; Morris, D.L. Review of patients with peritoneal malignancy treated with peritonectomy and heated intraperitoneal chemotherapy. ANZ J. Surg. 2006, 76, 156-161. [CrossRef] [PubMed]

53. Hagendoorn, J.; van Lammeren, G.; Boerma, D.; van der Beek, E.; Wiezer, M.J.; van Ramshorst, B. Cytoreductive surgery and hyperthermic intraperitoneal chemotherapy for peritoneal carcinomatosis from colorectal and gastrointestinal origin shows acceptable morbidity and high survival. Eur. J. Surg. Oncol. 2009, 35, 833-837. [CrossRef] [PubMed]

54. Hompes, D.; D’Hoore, A.; Wolthuis, A.; Fieuws, S.; Mirck, B.; Bruin, S.; Verwaal, V. The use of Oxaliplatin or Mitomycin C in HIPEC treatment for peritoneal carcinomatosis from colorectal cancer: A comparative study. J. Surg. Oncol. 2014, 109, 527-532. [CrossRef] 
55. Huang, Y.; Alzahrani, N.A.; Chua, T.C.; Liauw, W.; Morris, D.L. Impacts of low peritoneal cancer index on the survival outcomes of patient with peritoneal carcinomatosis of colorectal origin. Int. J. Surg. 2015, 23, 181-185. [CrossRef]

56. Iversen, L.H.; Rasmussen, P.C.; Hagemann-Madsen, R.; Laurberg, S. Cytoreductive surgery and hyperthermic intraperitoneal chemotherapy for peritoneal carcinomatosis: The Danish experience. Colorectal Dis. 2013, 15, e365-e372. [CrossRef]

57. Jacquet, P.; Averbach, A.; Stephens, A.D.; Stuart, O.A.; Chang, D.; Sugarbaker, P.H. Heated intraoperative intraperitoneal mitomycin $\mathrm{C}$ and early postoperative intraperitoneal 5-fluorouracil: Pharmacokinetic studies. Oncology 1998, 55, 130-138. [CrossRef]

58. Jacquet, P.; Stephens, A.D.; Averbach, A.M.; Chang, D.; Ettinghausen, S.E.; Dalton, R.R.; Steves, M.A.; Sugarbaker, P.H. Analysis of morbidity and mortality in 60 patients with peritoneal carcinomatosis treated by cytoreductive surgery and heated intraoperative intraperitoneal chemotherapy. Cancer 1996, 77, 2622-2629. [CrossRef]

59. Kecmanovic, D.M.; Pavlov, M.J.; Ceranic, M.S.; Sepetkovski, A.V.; Kovacevic, P.A.; Stamenkovic, A.B. Treatment of peritoneal carcinomatosis from colorectal cancer by cytoreductive surgery and hyperthermic perioperative intraperitoneal chemotherapy. Eur. J. Surg. Oncol. 2005, 31, 147-152. [CrossRef] [PubMed]

60. Klaver, Y.L.; Chua, T.C.; de Hingh, I.H.; Morris, D.L. Outcomes of elderly patients undergoing cytoreductive surgery and perioperative intraperitoneal chemotherapy for colorectal cancer peritoneal carcinomatosis. J. Surg. Oncol. 2012, 105, 113-118. [CrossRef]

61. Klaver, Y.L.; Lemmens, V.E.; Nienhuijs, S.W.; Nieuwenhuijzen, G.A.; Rutten, H.J.; de Hingh, I.H. Intraoperative radiotherapy and cytoreductive surgery with hyperthermic intraperitoneal chemotherapy. Five consecutive case reports of locally advanced rectal cancer with synchronous peritoneal carcinomatosis. Strahlentherapie und Onkologie 2013, 189, 256-260. [CrossRef] [PubMed]

62. Königsrainer, I.; Zieker, D.; Glatzle, J.; Lauk, O.; Klimek, J.; Symons, S.; Brücher, B.; Beckert, S.; Königsrainer, A. Experience after 100 patients treated with cytoreductive surgery and hyperthermic intraperitoneal chemotherapy. World J. Gastroenterol. 2012, 18, 2061-2066. [CrossRef] [PubMed]

63. Kuijpers, A.M.; Mehta, A.M.; Boot, H.; van Leerdam, M.E.; Hauptmann, M.; Aalbers, A.G.; Verwaal, V.J. Perioperative systemic chemotherapy in peritoneal carcinomatosis of lymph node positive colorectal cancer treated with cytoreductive surgery and hyperthermic intraperitoneal chemotherapy. Ann. Oncol. 2014, 25, 864-869. [CrossRef]

64. Kuijpers, A.M.; Mirck, B.; Aalbers, A.G.; Nienhuijs, S.W.; de Hingh, I.H.; Wiezer, M.J.; van Ramshorst, B.; van Ginkel, R.J.; Havenga, K.; Bremers, A.J.; et al. Cytoreduction and HIPEC in the Netherlands: Nationwide long-term outcome following the Dutch protocol. Ann. Surg. Oncol. 2013, 20, 4224-4230. [CrossRef]

65. Lam, J.Y.; McConnell, Y.J.; Rivard, J.D.; Temple, W.J.; Mack, L.A. Hyperthermic intraperitoneal chemotherapy + early postoperative intraperitoneal chemotherapy versus hyperthermic intraperitoneal chemotherapy alone: Assessment of survival outcomes for colorectal and high-grade appendiceal peritoneal carcinomatosis. Am. J. Surg. 2015, 210, 424-430. [CrossRef] [PubMed]

66. Leung, V.; Huo, Y.R.; Liauw, W.; Morris, D.L. Oxaliplatin versus Mitomycin C for HIPEC in colorectal cancer peritoneal carcinomatosis. Eur. J. Surg. Oncol. 2017, 43, 144-149. [CrossRef] [PubMed]

67. Levine, E.A.; Stewart, J.H., IV; Shen, P.; Russell, G.B.; Loggie, B.L.; Votanopoulos, K.I. Intraperitoneal chemotherapy for peritoneal surface malignancy: Experience with 1,000 patients. J. Am. Coll. Surg. 2014, 218, 573-585. [CrossRef]

68. Massalou, D.; Benizri, E.; Chevallier, A.; Duranton-Tanneur, V.; Pedeutour, F.; Benchimol, D.; Béréder, J.M. Peritoneal carcinomatosis of colorectal cancer: Novel clinical and molecular outcomes. Am. J. Surg. 2017, 213, 377-387. [CrossRef] [PubMed]

69. McConnell, Y.J.; Mack, L.A.; Francis, W.P.; Ho, T.; Temple, W.J. HIPEC + EPIC versus HIPEC-alone: Differences in major complications following cytoreduction surgery for peritoneal malignancy. J. Surg. Oncol. 2013, 107, 591-596. [CrossRef] [PubMed]

70. McQuellon, R.P.; Loggie, B.W.; Fleming, R.A.; Russell, G.B.; Lehman, A.B.; Rambo, T.D. Quality of life after intraperitoneal hyperthermic chemotherapy (IPHC) for peritoneal carcinomatosis. Eur. J. Surg. Oncol. 2001, 27, 65-73. [CrossRef] [PubMed] 
71. Moran, B.; Cecil, T.; Chandrakumaran, K.; Arnold, S.; Mohamed, F.; Venkatasubramaniam, A. The results of cytoreductive surgery and hyperthermic intraperitoneal chemotherapy in 1200 patients with peritoneal malignancy. Colorectal Dis. 2015, 17, 772-778. [CrossRef]

72. Navez, J.; Remue, C.; Leonard, D.; Bachmann, R.; Kartheuser, A.; Hubert, C.; Coubeau, L.; Komuta, M.; Van den Eynde, M.; Zech, F.; et al. Surgical Treatment of Colorectal Cancer with Peritoneal and Liver Metastases Using Combined Liver and Cytoreductive Surgery and Hyperthermic Intraperitoneal Chemotherapy: Report from a Single-Centre Experience. Ann. Surg. Oncol. 2016, 23, 666-673. [CrossRef] [PubMed]

73. Pelz, J.O.; Stojadinovic, A.; Nissan, A.; Hohenberger, W.; Esquivel, J. Evaluation of a peritoneal surface disease severity score in patients with colon cancer with peritoneal carcinomatosis. J. Surg. Oncol. 2009, 99, 9-15. [CrossRef] [PubMed]

74. Pestieau, S.R.; Sugarbaker, P.H. Treatment of primary colon cancer with peritoneal carcinomatosis: Comparison of concomitant vs. delayed management. Dis. Colon Rectum 2000, 43, 1341-1348. [CrossRef] [PubMed]

75. Prada-Villaverde, A.; Esquivel, J.; Lowy, A.M.; Markman, M.; Chua, T.; Pelz, J.; Baratti, D.; Baumgartner, J.M.; Berri, R.; Bretcha-Boix, P.; et al. The American Society of Peritoneal Surface Malignancies evaluation of HIPEC with Mitomycin C versus Oxaliplatin in 539 patients with colon cancer undergoing a complete cytoreductive surgery. J. Surg. Oncol. 2014, 110, 779-785. [CrossRef]

76. Rouers, A.; Laurent, S.; Detroz, B.; Meurisse, M. Cytoreductive surgery and hyperthermic intraperitoneal chemotherapy for colorectal peritoneal carcinomatosis: Higher complication rate for oxaliplatin compared to Mitomycin, C. Acta Chirurgica Belgica 2006, 106, 302-306. [CrossRef] [PubMed]

77. Saxena, A.; Yan, T.D.; Morris, D.L. A critical evaluation of risk factors for complications after cytoreductive surgery and perioperative intraperitoneal chemotherapy for colorectal peritoneal carcinomatosis. World J. Surg. 2010, 34, 70-78. [CrossRef] [PubMed]

78. Schneebaum, S.; Arnold, M.W.; Staubus, A.; Young, D.C.; Dumond, D.; Martin, E.W., Jr. Intraperitoneal hyperthermic perfusion with mitomycin $\mathrm{C}$ for colorectal cancer with peritoneal metastases. Ann. Surg. Oncol. 1996, 3, 44-50. [CrossRef] [PubMed]

79. Shen, P.; Hawksworth, J.; Lovato, J.; Loggie, B.W.; Geisinger, K.R.; Fleming, R.A.; Levine, E.A. Cytoreductive surgery and intraperitoneal hyperthermic chemotherapy with mitomycin $\mathrm{C}$ for peritoneal carcinomatosis from nonappendiceal colorectal carcinoma. Ann. Surg. Oncol. 2004, 11, 178-186. [CrossRef] [PubMed]

80. Shen, P.; Levine, E.A.; Hall, J.; Case, D.; Russell, G.; Fleming, R.; McQuellon, R.; Geisinger, K.R.; Loggie, B.W. Factors predicting survival after intraperitoneal hyperthermic chemotherapy with mitomycin $C$ after cytoreductive surgery for patients with peritoneal carcinomatosis. Arch. Surg. 2003, 138, 26-33. [CrossRef]

81. Simkens, G.A.; van Oudheusden, T.R.; Braam, H.J.; Wiezer, M.J.; Nienhuijs, S.W.; Rutten, H.J.; van Ramshorst, B.; de Hingh, I.H. Cytoreductive surgery and HIPEC offers similar outcomes in patients with rectal peritoneal metastases compared to colon cancer patients: A matched case control study. J. Surg. Oncol. 2016, 113, 548-553. [CrossRef]

82. Simkens, G.A.; van Oudheusden, T.R.; Nieboer, D.; Steyerberg, E.W.; Rutten, H.J.; Luyer, M.D.; Nienhuijs, S.W.; de Hingh, I.H. Development of a Prognostic Nomogram for Patients with Peritoneally Metastasized Colorectal Cancer Treated with Cytoreductive Surgery and HIPEC. Ann. Surg. Oncol. 2016, 23, 4214-4221. [CrossRef] [PubMed]

83. Spiliotis, J.; Tentes, A.A.; Vaxevanidou, A.; Korakianitis, O.S.; Rogdakis, A.; Mirelis, C.G.; Datsis, A.C.; Kekelos, S. Cytoreductive surgery and hyperthermic intraperitoneal chemotherapy in the management of peritoneal carcinomatosis. Preliminary results and cost from two centers in Greece. J. BUON 2008, 13, 205-210. [PubMed]

84. Tabrizian, P.; Jibara, G.; Shrager, B.; Franssen, B.; Yang, M.J.; Sarpel, U.; Hiotis, S.; Labow, D. Outcomes for cytoreductive surgery and hyperthermic intraperitoneal chemotherapy in the elderly. Surg. Oncol. 2013, 22, 184-189. [CrossRef]

85. Tabrizian, P.; Shrager, B.; Jibara, G.; Yang, M.J.; Romanoff, A.; Hiotis, S.; Sarpel, U.; Labow, D.M. Cytoreductive surgery and hyperthermic intraperitoneal chemotherapy for peritoneal carcinomatosis: Outcomes from a single tertiary institution. J. Gastrointest. Surg. 2014, 18, 1024-1031. [CrossRef]

86. Tan, G.; Chia, C.; Kumar, M.; Choo, S.P.; Chia, J.; Tham, C.K.; Chua, C.; Soo, K.C.; Teo, M. 201 consecutive cytoreductive surgery (CRS) and hyperthermic intraperitoneal chemotherapy (HIPEC) procedures in a single Asian tertiary centre. Int. J. Hyperth. 2016, 33, 1-7. [CrossRef] [PubMed] 
87. Teo, M.C.; Ching Tan, G.H.; Lim, C.; Chia, C.S.; Tham, C.K.; Soo, K.C. Colorectal peritoneal carcinomatosis treated with cytoreductive surgery and hyperthermic intraperitoneal chemotherapy: The experience of a tertiary Asian center. Asian J. Surg. 2015, 38, 65-73. [CrossRef]

88. Teo, M.C.; Tan, G.H.; Tham, C.K.; Lim, C.; Soo, K.C. Cytoreductive surgery and hyperthermic intraperitoneal chemotherapy in Asian patients: 100 consecutive patients in a single institution. Ann. Surg. Oncol. 2013, 20, 2968-2974. [CrossRef] [PubMed]

89. Tuttle, T.M.; Zhang, Y.; Greeno, E.; Knutsen, A. Toxicity and quality of life after cytoreductive surgery plus hyperthermic intraperitoneal chemotherapy. Ann. Surg. Oncol. 2006, 13, 1627-1632. [CrossRef]

90. Ung, L.; Chua, T.C.; Morris, D.L. Peritoneal metastases of lower gastrointestinal tract origin: A comparative study of patient outcomes following cytoreduction and intraperitoneal chemotherapy. J. Cancer Res. Clin. Oncol. 2013, 139, 1899-1908. [CrossRef]

91. Vaira, M.; Cioppa, T.; D’Amico, S.; de Marco, G.; D'Alessandro, M.; Fiorentini, G.; De Simone, M. Treatment of peritoneal carcinomatosis from colonic cancer by cytoreduction, peritonectomy and hyperthermic intraperitoneal chemotherapy (HIPEC). Experience of ten years. In Vivo 2010, 24, 79-84. [PubMed]

92. Van Oudheusden, T.R.; Braam, H.J.; Nienhuijs, S.W.; Wiezer, M.J.; van Ramshorst, B.; Luyer, M.D.; Lemmens, V.E.; de Hingh, I.H. Cytoreduction and hyperthermic intraperitoneal chemotherapy: A feasible and effective option for colorectal cancer patients after emergency surgery in the presence of peritoneal carcinomatosis. Ann. Surg. Oncol. 2014, 21, 2621-2626. [CrossRef] [PubMed]

93. Van Oudheusden, T.R.; Braam, H.J.; Nienhuijs, S.W.; Wiezer, M.J.; van Ramshorst, B.; Luyer, P.; de Hingh, I.H. Poor outcome after cytoreductive surgery and HIPEC for colorectal peritoneal carcinomatosis with signet ring cell histology. J. Surg. Oncol. 2015, 111, 237-242. [CrossRef] [PubMed]

94. Van Ruth, S.; Mathot, R.A.; Sparidans, R.W.; Beijnen, J.H.; Verwaal, V.J.; Zoetmulder, F.A. Population pharmacokinetics and pharmacodynamics of mitomycin during intraoperative hyperthermic intraperitoneal chemotherapy. Clin. Pharmacokinet. 2004, 43, 131-143. [CrossRef]

95. Van Sweringen, H.L.; Hanseman, D.J.; Ahmad, S.A.; Edwards, M.J.; Sussman, J.J. Predictors of survival in patients with high-grade peritoneal metastases undergoing cytoreductive surgery and hyperthermic intraperitoneal chemotherapy. Surgery 2012, 152, 617-625. [CrossRef]

96. van Vugt, J.L.; Braam, H.J.; van Oudheusden, T.R.; Vestering, A.; Bollen, T.L.; Wiezer, M.J.; de Hingh, I.H.; van Ramshorst, B.; Boerma, D. Skeletal Muscle Depletion is Associated with Severe Postoperative Complications in Patients Undergoing Cytoreductive Surgery with Hyperthermic Intraperitoneal Chemotherapy for Peritoneal Carcinomatosis of Colorectal Cancer. Ann. Surg. Oncol. 2015, 22, 3625-3631. [CrossRef] [PubMed]

97. Varban, O.; Levine, E.A.; Stewart, J.H.; McCoy, T.P.; Shen, P. Outcomes associated with cytoreductive surgery and intraperitoneal hyperthermic chemotherapy in colorectal cancer patients with peritoneal surface disease and hepatic metastases. Cancer 2009, 115, 3427-3436. [PubMed]

98. Verwaal, V.J.; Bruin, S.; Boot, H.; van Slooten, G.; van Tinteren, H. 8-year follow-up of randomized trial: Cytoreduction and hyperthermic intraperitoneal chemotherapy versus systemic chemotherapy in patients with peritoneal carcinomatosis of colorectal cancer. Ann. Surg. Oncol. 2008, 15, 2426-2432. [CrossRef] [PubMed]

99. Verwaal, V.J.; van Tinteren, H.; van Ruth, S.; Zoetmulder, F.A. Predicting the survival of patients with peritoneal carcinomatosis of colorectal origin treated by aggressive cytoreduction and hyperthermic intraperitoneal chemotherapy. Br. J. Surg. 2004, 91, 739-746. [CrossRef] [PubMed]

100. Winer, J.; Zenati, M.; Ramalingam, L.; Jones, H.; Zureikat, A.; Holtzman, M.; Lee, K.; Ahrendt, S.; Pingpank, J.; Zeh, H.J.; et al. Impact of aggressive histology and location of primary tumor on the efficacy of surgical therapy for peritoneal carcinomatosis of colorectal origin. Ann. Surg. Oncol. 2014, 21, 1456-1462. [CrossRef] [PubMed]

101. Yan, T.D.; Chu, F.; Links, M.; Kam, P.C.; Glenn, D.; Morris, D.L. Cytoreductive surgery and perioperative intraperitoneal chemotherapy for peritoneal carcinomatosis from colorectal carcinoma: Non-mucinous tumour associated with an improved survival. Eur. J. Surg. Oncol. 2006, 32, 1119-1124. [CrossRef] [PubMed]

102. Yan, T.D.; Morris, D.L. Cytoreductive surgery and perioperative intraperitoneal chemotherapy for isolated colorectal peritoneal carcinomatosis: Experimental therapy or standard of care? Ann. Surg. 2008, 248, 829-835. [PubMed] 
103. Zanon, C.; Bortolini, M.; Chiappino, I.; Simone, P.; Bruno, F.; Gaglia, P.; Airoldi, M.; Deriu, L.; Mashiah, A. Cytoreductive surgery combined with intraperitoneal chemohyperthermia for the treatment of advanced colon cancer. World J. Surg. 2006, 30, 2025-2032. [CrossRef] [PubMed]

104. Asero, S.; Caruso, M.; Vallone, N.; Luciani, A.G.; Lombardo, V.; Terranova, G.; Ettore, G.; Giannone, G. Cytoreductive surgery (cs) and hyperthermic intraperitoneal chemotherapy (hipec) in treatment of peritoneal surface malignances: Report of a phase II clinical study. In Vivo 2009, 23, 645-647. [PubMed]

105. Baratti, D.; Kusamura, S.; Iusco, D.; Bonomi, S.; Grassi, A.; Virzì, S.; Leo, E.; Deraco, M. Postoperative complications after cytoreductive surgery and hyperthermic intraperitoneal chemotherapy affect long-term outcome of patients with peritoneal metastases from colorectal cancer: A two-center study of 101 patients. Dis. Colon Rectum 2014, 57, 858-868. [CrossRef] [PubMed]

106. Baratti, D.; Kusamura, S.; Iusco, D.; Gimondi, S.; Pietrantonio, F.; Milione, M.; Guaglio, M.; Bonomi, S.; Grassi, A.; Virzì, S. Hyperthermic Intraperitoneal Chemotherapy (HIPEC) at the Time of Primary Curative Surgery in Patients with Colorectal Cancer at High Risk for Metachronous Peritoneal Metastases. Ann. Surg. Oncol. 2017, 24, 167-175. [CrossRef] [PubMed]

107. Bouhadjari, N.; Gabato, W.; Calabrese, D.; Msika, S.; Keita, H. Hyperthermic intraperitoneal chemotherapy with cisplatin: Amifostine prevents acute severe renal impairment. Eur. J. Surg. Oncol. 2016, 42, $219-223$. [CrossRef] [PubMed]

108. Cavaliere, F.; De Simone, M.; Virzì, S.; Deraco, M.; Rossi, C.R.; Garofalo, A.; Di Filippo, F.; Giannarelli, D.; Vaira, M.; Valle, M.; et al. Prognostic factors and oncologic outcome in 146 patients with colorectal peritoneal carcinomatosis treated with cytoreductive surgery combined with hyperthermic intraperitoneal chemotherapy: Italian multicenter study S.I.T.I.L.O. Eur. J. Surg. Oncol. 2011, 37, 148-154. [CrossRef] [PubMed]

109. Cavaliere, F.; Di Filippo, F.; Botti, C.; Cosimelli, M.; Giannarelli, D.; Aloe, L.; Arcuri, E.; Aromatario, C.; Consolo, S.; Callopoli, A.; et al. Peritonectomy and hyperthermic antiblastic perfusion in the treatment of peritoneal carcinomatosis. Eur. J. Surg. Oncol. 2000, 26, 486-491. [CrossRef] [PubMed]

110. Cavaliere, F.; Perri, P.; Di Filippo, F.; Giannarelli, D.; Botti, C.; Cosimelli, M.; Tedesco, M.; Principi, F.; Laurenzi, L.; Cavaliere, R. Treatment of peritoneal carcinomatosis with intent to cure. J. Surg. Oncol. 2000, 74, 41-44. [CrossRef]

111. Cavaliere, F.; Valle, M.; De Simone, M.; Deraco, M.; Rossi, C.R.; Di Filippo, F.; Verzi, S.; Giannarelli, D.; Perri, P.; Pilati, P.L.; et al. 120 peritoneal carcinomatoses from colorectal cancer treated with peritonectomy and intra-abdominal chemohyperthermia: A S.I.T.I.L.O. multicentric study. In Vivo 2006, 20, 747-750.

112. Elias, D.; Gilly, F.; Boutitie, F.; Quénet, F.; Bereder, J.M.; Mansvelt, B.; Lorimier, G.; Dubè, P.; Glehen, O. Peritoneal colorectal carcinomatosis treated with surgery and perioperative intraperitoneal chemotherapy: Retrospective analysis of 523 patients from a multicentric French study. J. Clin. Oncol. 2010, 28, 63-68. [CrossRef] [PubMed]

113. Huang, C.Q.; Yang, X.J.; Yu, Y.; Wu, H.T.; Liu, Y.; Yonemura, Y.; Li, Y. Cytoreductive surgery plus hyperthermic intraperitoneal chemotherapy improves survival for patients with peritoneal carcinomatosis from colorectal cancer: A phase II study from a Chinese center. PLoS ONE 2014, 9, e108509. [CrossRef]

114. Kianmanesh, R.; Scaringi, S.; Sabate, J.M.; Castel, B.; Pons-Kerjean, N.; Coffin, B.; Hay, J.M.; Flamant, Y.; Msika, S. Iterative cytoreductive surgery associated with hyperthermic intraperitoneal chemotherapy for treatment of peritoneal carcinomatosis of colorectal origin with or without liver metastases. Ann. Surg. 2007, 245, 597-603. [CrossRef]

115. Lin, E.K.; Hsieh, M.C.; Chen, C.H.; Lu, Y.J.; Wu, S.Y. Outcomes of cytoreductive surgery and hyperthermic intraperitoneal chemotherapy for colorectal cancer with peritoneal metastasis. Medicine 2016, 95, e5522. [CrossRef] [PubMed]

116. Lorimier, G.; Linot, B.; Paillocher, N.; Dupoiron, D.; Verri èle, V.; Wernert, R.; Hamy, A.; Capitain, O. Curative cytoreductive surgery followed by hyperthermic intraperitoneal chemotherapy in patients with peritoneal carcinomatosis and synchronous resectable liver metastases arising from colorectal cancer. Eur. J. Surg. Oncol. 2017, 43, 150-158. [CrossRef]

117. Pilati, P.; Mocellin, S.; Rossi, C.R.; Foletto, M.; Campana, L.; Nitti, D.; Lise, M. Cytoreductive surgery combined with hyperthermic intraperitoneal intraoperative chemotherapy for peritoneal carcinomatosis arising from colon adenocarcinoma. Ann. Surg. Oncol. 2003, 10, 508-513. [CrossRef] [PubMed] 
118. Robella, M.; Vaira, M.; Marsanic, P.; Mellano, A.; Cinquegrana, A.; Sottile, A.; De Simone, M. Treatment of peritoneal carcinomatosis from colonic cancer by cytoreduction, peritonectomy and HIPEC: Preliminary results in highly selected patients. Minerva Chir. 2013, 68, 551-558.

119. Yamaguchi, A.; Tsukioka, Y.; Fushida, S.; Kurosaka, Y.; Kanno, M.; Yonemura, Y.; Miwa, K.; Miyazaki, I. Intraperitoneal hyperthermic treatment for peritoneal dissemination of colorectal cancers. Dis. Colon Rectum 1992, 35, 964-968. [CrossRef] [PubMed]

120. Yonemura, Y.; Canbay, E.; Ishibashi, H. Prognostic factors of peritoneal metastases from colorectal cancer following cytoreductive surgery and perioperative chemotherapy. Sci. World J. 2013, 2013, 978394. [CrossRef]

121. Majerović, M.; Milinović, D.; Oresković, S.; Matosević, P.; Mirić, M.; Kekez, T.; Kinda, E.; Augustin, G.; Silovski, H. Hyperthermic intraperitoneal chemotherapy (HIPEC) and cytoreductive surgery (CS) as treatment of peritoneal carcinomatosis: Preliminary results in Croatia. Coll. Antropol. 2011, 35, 1349-1352. [PubMed]

122. Melero, J.T.; Ortega, F.G.; Gonzalez, A.M.; Carmona-Saez, P.; Garcia Puche, J.L.; Sugarbaker, P.H.; Delgado, M.; Lorente, J.A.; Serrano, M.J. Prognostic factor analysis of circulating tumor cells in peripheral blood of patients with peritoneal carcinomatosis of colon cancer origin treated with cytoreductive surgery plus an intraoperative hyperthermic intraperitoneal chemotherapy procedure (CRS + HIPEC). Surgery 2016, 159, 728-735.

123. Piso, P.; Dahlke, M.H.; Ghali, N.; Iesalnieks, I.; Loss, M.; Popp, F.; von Breitenbuch, P.; Agha, A.; Lang, S.A.; Kullmann, F.; et al. Multimodality treatment of peritoneal carcinomatosis from colorectal cancer: First results of a new German centre for peritoneal surface malignancies. Int. J. Colorectal Dis. 2007, 22, 1295-1300. [CrossRef]

124. Sugarbaker, P.H.; Van der Speeten, K.; Anthony Stuart, O.; Chang, D. Impact of surgical and clinical factors on the pharmacology of intraperitoneal doxorubicin in 145 patients with peritoneal carcinomatosis. Eur. J. Surg. Oncol. 2011, 37, 719-726. [CrossRef]

125. Shimizu, T.; Murata, S.; Sonoda, H.; Mekata, E.; Ohta, H.; Takebayashi, K.; Miyake, T.; Tani, T. Hyperthermic intraperitoneal chemotherapy with mitomycin $\mathrm{C}$ and 5-fluorouracil in patients at high risk of peritoneal metastasis from colorectal cancer: A preliminary clinical study. Mol. Clin. Oncol. 2014, 2, 399-404. [CrossRef]

126. Yang, X.J.; Li, Y.; al-shammaa Hassan, A.H.; Yang, G.L.; Liu, S.Y.; Lu, Y.L.; Zhang, J.W.; Yonemura, Y. Cytoreductive surgery plus hyperthermic intraperitoneal chemotherapy improves survival in selected patients with peritoneal carcinomatosis from abdominal and pelvic malignancies: Results of 21 cases. Ann. Surg. Oncol. 2009, 16, 345-351. [CrossRef] [PubMed]

127. Alzahrani, N.; Ferguson, J.S.; Valle, S.J.; Liauw, W.; Chua, T.; Morris, D.L. Cytoreductive surgery and hyperthermic intraperitoneal chemotherapy: Long-term results at St George Hospital, Australia. ANZ J. Surg. 2016, 86, 937-941. [CrossRef] [PubMed]

128. Ceelen, W.P.; Peeters, M.; Houtmeyers, P.; Breusegem, C.; De Somer, F.; Pattyn, P. Safety and efficacy of hyperthermic intraperitoneal chemoperfusion with high-dose oxaliplatin in patients with peritoneal carcinomatosis. Ann. Surg. Oncol. 2008, 15, 535-541. [CrossRef] [PubMed]

129. Elias, D.; Benizri, E.; Di Pietrantonio, D.; Menegon, P.; Malka, D.; Raynard, B. Comparison of two kinds of intraperitoneal chemotherapy following complete cytoreductive surgery of colorectal peritoneal carcinomatosis. Ann. Surg. Oncol. 2007, 14, 509-514. [CrossRef] [PubMed]

130. Elias, D.; Benizri, E.; Pocard, M.; Ducreux, M.; Boige, V.; Lasser, P. Treatment of synchronous peritoneal carcinomatosis and liver metastases from colorectal cancer. Eur. J. Surg. Oncol. 2006, 32, 632-636. [CrossRef] [PubMed]

131. Elias, D.; Bonnay, M.; Puizillou, J.M.; Antoun, S.; Demirdjian, S.; El, O.A.; Pignon, J.P.; Drouard-Troalen, L.; Ouellet, J.F.; Ducreux, M. Heated intra-operative intraperitoneal oxaliplatin after complete resection of peritoneal carcinomatosis: Pharmacokinetics and tissue distribution. Ann. Oncol. 2002, 13, 267-272. [CrossRef] [PubMed]

132. Elias, D.; El Otmany, A.; Bonnay, M.; Paci, A.; Ducreux, M.; Antoun, S.; Lasser, P.; Laurent, S.; Bourget, P. Human pharmacokinetic study of heated intraperitoneal oxaliplatin in increasingly hypotonic solutions after complete resection of peritoneal carcinomatosis. Oncology 2002, 63, 346-352. [CrossRef]

133. Elias, D.; Lefevre, J.H.; Chevalier, J.; Brouquet, A.; Marchal, F.; Classe, J.M.; Ferron, G.; Guilloit, J.M.; Meeus, P.; Goéré, D.; et al. Complete cytoreductive surgery plus intraperitoneal chemohyperthermia with oxaliplatin for peritoneal carcinomatosis of colorectal origin. J. Clin. Oncol. 2009, 27, 681-685. [CrossRef] 
134. Elias, D.; Mariani, A.; Cloutier, A.S.; Blot, F.; Goéré, D.; Dumont, F.; Honoré, C.; Billard, V.; Dartigues, P.; Ducreux, M. Modified selection criteria for complete cytoreductive surgery plus HIPEC based on peritoneal cancer index and small bowel involvement for peritoneal carcinomatosis of colorectal origin. Eur. J. Surg. Oncol. 2014, 40, 1467-1473. [CrossRef]

135. Elias, D.; Pocard, M.; Sideris, L.; Edè, C.; Ducreux, M.; Boige, V.; Lasser, P. Preliminary results of intraperitoneal chemohyperthermia with oxaliplatin in peritoneal carcinomatosis of colorectal origin. Br. J. Surg. 2004, 91, 455-456. [CrossRef]

136. Elias, D.; Raynard, B.; Farkhondeh, F.; Goéré, D.; Rouquie, D.; Ciuchendea, R.; Pocard, M.; Ducreux, M. Peritoneal carcinomatosis of colorectal origin: Long-term results of intraperitoneal chemohyperthermia with oxaliplatin following complete cytoreductive surgery. Gastroentérologie Clinique et Biologique 2006, 30, 1200-1204. [CrossRef]

137. Elias, D.; Sideris, L.; Pocard, M.; Edè, C.; Ben Hassouna, D.; Ducreux, M.; Boige, V.; Côté, J.F.; Lasser, P. Efficacy of intraperitoneal chemohyperthermia with oxaliplatin in colorectal peritoneal carcinomatosis. Preliminary results in 24 patients. Ann. Oncol. 2004, 15, 781-785. [CrossRef] [PubMed]

138. Gervais, M.K.; Dube, P.; McConnell, Y.; Drolet, P.; Mitchell, A.; Sideris, L. Cytoreductive surgery plus hyperthermic intraperitoneal chemotherapy with oxaliplatin for peritoneal carcinomatosis arising from colorectal cancer. J. Surg. Oncol. 2013, 108, 438-443. [CrossRef]

139. Glockzin, G.; Gerken, M.; Lang, S.A.; Klinkhammer-Schalke, M.; Piso, P.; Schlitt, H.J. Oxaliplatin-based versus irinotecan-based hyperthermic intraperitoneal chemotherapy (HIPEC) in patients with peritoneal metastasis from appendiceal and colorectal cancer: A retrospective analysis. BMC Cancer 2014, 14, 807. [CrossRef] [PubMed]

140. Goéré, D.; Malka, D.; Tzanis, D.; Gava, V.; Boige, V.; Eveno, C.; Maggiori, L.; Dumont, F.; Ducreux, M.; Elias, D. Is there a possibility of a cure in patients with colorectal peritoneal carcinomatosis amenable to complete cytoreductive surgery and intraperitoneal chemotherapy? Ann. Surg. 2013, 257, 1065-1071. [CrossRef]

141. Hompes, D.; D’Hoore, A.; Van Cutsem, E.; Fieuws, S.; Ceelen, W.; Peeters, M.; Van der Speeten, K.; Bertrand, C.; Legendre, H.; Kerger, J. The treatment of peritoneal carcinomatosis of colorectal cancer with complete cytoreductive surgery and hyperthermic intraperitoneal peroperative chemotherapy (HIPEC) with oxaliplatin: A Belgian multicentre prospective phase II clinical study. Ann. Surg. Oncol. 2012, 19, 2186-2194. [CrossRef]

142. Mehta, A.M.; Huitema, A.D.; Burger, J.W.; Brandt-Kerkhof, A.R.; van den Heuvel, S.F.; Verwaal, V.J. Standard Clinical Protocol for Bidirectional Hyperthermic Intraperitoneal Chemotherapy (HIPEC): Systemic Leucovorin, 5-Fluorouracil, and Heated Intraperitoneal Oxaliplatin in a Chloride-Containing Carrier Solution. Ann. Surg. Oncol. 2017, 24, 990-997. [CrossRef] [PubMed]

143. Nikolic, S.; Dzodic, R.; Zegarac, M.; Djurisic, I.; Gavrilovic, D.; Vojinovic, V.; Kocic, M.; Santrac, N.; Radlovic, P.; Radosavljevic, D.; et al. Survival prognostic factors in patients with colorectal peritoneal carcinomatosis treated with cytoreductive surgery and intraoperative hyperthermic intraperitoneal chemotherapy: A single institution experience. J. BUON 2014, 19, 66-74. [CrossRef]

144. Quénet, F.; Goéré, D.; Mehta, S.S.; Roca, L.; Dumont, F.; Hessissen, M.; Saint-Aubert, B.; Elias, D. Results of two bi-institutional prospective studies using intraperitoneal oxaliplatin with or without irinotecan during HIPEC after cytoreductive surgery for colorectal carcinomatosis. Ann. Surg. 2011, 254, 294-301. [CrossRef]

145. Somashekhar, S.P.; Prasanna, G.; Jaka, R.; Rauthan, A.; Murthy, H.S.; Karanth, S. Hyperthermic intraperitoneal chemotherapy for peritoneal surface malignancies: A single institution Indian experience. Natl. Med. J. India 2016, 29, 262-266.

146. Stewart, J.H., IV; Shen, P.; Russell, G.; Fenstermaker, J.; McWilliams, L.; Coldrun, F.M.; Levine, K.E.; Jones, B.T.; Levine, E.A. A phase I trial of oxaliplatin for intraperitoneal hyperthermic chemoperfusion for the treatment of peritoneal surface dissemination from colorectal and appendiceal cancers. Ann. Surg. Oncol. 2008, 15, 2137-2145. [CrossRef] [PubMed]

147. Topgül, K.; Çetinkaya, M.B.; Ciğdem Arslan, N.; Gül, M.K.; Çan, M.; Gürsel, M.F.; Erdem, D.; Malazgirt, Z. Cytoreductive surgery (SRC) and hyperthermic intraperitoneal chemotherapy (HIPEC) for treatment of peritoneal carcinomatosis: Our initial experience and technical details. Turk. J. Surg. 2015, 31, 138-147. [CrossRef] [PubMed] 
148. Turrini, O.; Lambaudie, E.; Faucher, M.; Viret, F.; Blache, J.L.; Houvenaeghel, G.; Delpero, J.R. Initial experience with hyperthermic intraperitoneal chemotherapy. Arch. Surg. 2012, 147, 919-923. [CrossRef] [PubMed]

149. Chemama, S.; Bayar, M.A.; Lanoy, E.; Ammari, S.; Stoclin, A.; Goéré, D.; Elias, D.; Raynard, B.; Antoun, S. Sarcopenia is Associated with Chemotherapy Toxicity in Patients Undergoing Cytoreductive Surgery with Hyperthermic Intraperitoneal Chemotherapy for Peritoneal Carcinomatosis from Colorectal Cancer. Ann. Surg. Oncol. 2016, 23, 3891-3898. [CrossRef] [PubMed]

150. Elias, D.; Matsuhisa, T.; Sideris, L.; Liberale, G.; Drouard-Troalen, L.; Raynard, B.; Pocard, M.; Puizillou, J.M.; Billard, V.; Bourget, P.; et al. Heated intra-operative intraperitoneal oxaliplatin plus irinotecan after complete resection of peritoneal carcinomatosis: Pharmacokinetics, tissue distribution and tolerance. Ann. Oncol. 2004, 15, 1558-1565. [CrossRef]

151. Sardi, A.; Jimenez, W.; Nieroda, C.; Sittig, M.; Shankar, S.; Gushchin, V. Melphalan: A promising agent in patients undergoing cytoreductive surgery and hyperthermic intraperitoneal chemotherapy. Ann. Surg. Oncol. 2014, 21, 908-914. [CrossRef] [PubMed]

152. Füzün, M.; Sökmen, S.; Terzi, C.; Canda, A.E. Cytoreductive approach to peritoneal carcinomatosis originated from colorectal cancer: Turkish experience. Acta Chir. Iugosl. 2006, 53, 17-21. [CrossRef] [PubMed]

153. Cravioto-Villanueva, A.; Cavazos, M.; Luna-Perez, P.; Martinez-Gomez, H.; Ramirez, M.L.; Solorzano, J.; Montiel, H.; Esquivel, J. Cytoreductive surgery with hyperthermic intraperitoneal chemotherapy (HIPEC) delivered via a modified perfusion system for peritoneal carcinomatosis of colorectal origin. Surg. Today 2016, 46, 979-984. [CrossRef]

154. Murata, S.; Yamamoto, H.; Naitoh, H.; Yamaguchi, T.; Kaida, S.; Shimizu, T.; Shiomi, H.; Naka, S.; Tani, T.; Tani, M. Feasibility and safety of hyperthermic intraperitoneal chemotherapy using 5-fluorouracil combined with cisplatin and mitomycin $\mathrm{C}$ in patients undergoing gastrectomy for advanced gastric cancer. J. Surg. Oncol. 2017, 116, 1159-1165. [CrossRef]

155. Kusamura, S.; Dominique, E.; Baratti, D.; Younan, R.; Deraco, M. Drugs, carrier solutions and temperature in hyperthermic intraperitoneal chemotherapy. J. Surg. Oncol. 2008, 98, 247-252. [CrossRef]

156. Glehen, O.; Cotte, E.; Kusamura, S.; Deraco, M.; Baratti, D.; Passot, G.; Beaujard, A.C.; Noel, G.F. Hyperthermic intraperitoneal chemotherapy: Nomenclature and modalities of perfusion. J. Surg. Oncol. 2008, 98, 242-246. [CrossRef] [PubMed]

157. De Simone, M.; Vaira, M.; Caponi, A.; Ciaccio, B.; Fiorentini, G.; Turrisi, G.; Ferri, L.; Buti, G. Ten years experience in the treatment of pseudomyxoma peritonei by cytoreduction, peritonectomy and semi-closed hyperthermic antiblastic peritoneal perfusion. In Vivo 2006, 20, 725-727. [PubMed]

158. Benoit, L.; Cheynel, N.; Ortega-Deballon, P.; Giacomo, G.D.; Chauffert, B.; Rat, P. Closed hyperthermic intraperitoneal chemotherapy with open abdomen: A novel technique to reduce exposure of the surgical team to chemotherapy drugs. Ann. Surg. Oncol. 2008, 15, 542-546. [CrossRef] [PubMed]

159. Ortega-Deballon, P.; Facy, O.; Jambet, S.; Magnin, G.; Cotte, E.; Beltramo, J.L.; Chauffert, B.; Rat, P. Which method to deliver hyperthermic intraperitoneal chemotherapy with oxaliplatin? An experimental comparison of open and closed techniques. Ann. Surg. Oncol. 2010, 17, 1957-1963. [CrossRef]

160. Becouarn, Y.; Rougier, P. Clinical efficacy of oxaliplatin monotherapy: Phase II trials in advanced colorectal cancer. Semin. Oncol. 1998, 25, 23-31. [PubMed]

161. Charrier, T.; Passot, G.; Peron, J.; Maurice, C.; Gocevska, S.; Quénet, F.; Eveno, C.; Pocard, M.; Goéré, D.; Elias, D.; et al. Cytoreductive Surgery Combined with Hyperthermic Intraperitoneal Chemotherapy with Oxaliplatin Increases the Risk of Postoperative Hemorrhagic Complications: Analysis of Predictive Factors. Ann. Surg. Oncol. 2016, 23, 2315-2322. [CrossRef]

162. Loggie, B.W.; Thomas, P. Gastrointestinal Cancers with Peritoneal Carcinomatosis: Surgery and Hyperthermic Intraperitoneal Chemotherapy. Oncology 2015, 29, 515-521. [PubMed]

163. Maciver, A.H.; Al-Sukhni, E.; Esquivel, J.; Skitzki, J.J.; Kane, J.M., 3rd; Francescutti, V.A. Current Delivery of Hyperthermic Intraperitoneal Chemotherapy with Cytoreductive Surgery (CS/HIPEC) and Perioperative Practices: An International Survey of High-Volume Surgeons. Ann. Surg. Oncol. 2017, 24, 923-930. [CrossRef]

164. Fotopoulou, C.; Sehouli, J.; Mahner, S.; Harter, P.; Van Nieuwenhuysen, E.; Gonzalez-Martin, A.; Vergote, I.; Chiva, L.; Du Bois, A. HIPEC: HOPE or HYPE in the fight against advanced ovarian cancer? Ann. Oncol. 2018, 29, 1610-1613. [CrossRef] 
165. Wu, M.H.; Yan, B.; Humerickhouse, R.; Dolan, M.E. Irinotecan activation by human carboxylesterases in colorectal adenocarcinoma cells. Clin. Cancer Res. 2002, 8, 2696-2700.

166. Czejka, M.; Kiss, A.; Koessner, C.; Terkola, R.; Ettlinger, D.; Schueller, J. Metabolic activation of irinotecan during intra-arterial chemotherapy of metastatic colorectal cancer. Anticancer Res. 2011, 31, 3573-3578. [PubMed]

167. Mehta, A.M.; Van den Hoven, J.M.; Rosing, H.; Hillebrand, M.J.; Nuijen, B.; Huitema, A.D.; Beijnen, J.H.; Verwaal, V.J. Stability of oxaliplatin in chloride-containing carrier solutions used in hyperthermic intraperitoneal chemotherapy. Int. J. Pharm. 2015, 479, 23-27. [CrossRef] [PubMed]

168. Löffler, M.W.; Schuster, H.; Zeck, A.; Quilitz, N.; Weinreich, J.; Tolios, A.; Haen, S.P.; Horvath, P.; Löb, S.; Rammensee, H.G.; et al. Pharmacodynamics of Oxaliplatin-Derived Platinum Compounds During Hyperthermic Intraperitoneal Chemotherapy (HIPEC): An Emerging Aspect Supporting the Rational Design of Treatment Protocols. Ann. Surg. Oncol. 2017, 24, 1650-1657. [CrossRef] [PubMed]

169. Tentes, A.A.; Spiliotis, I.D.; Korakianitis, O.S.; Vaxevanidou, A.; Kyziridis, D. Adjuvant perioperative intraperitoneal chemotherapy in locally advanced colorectal carcinoma: Preliminary results. ISRN Surg. 2011, 2011, 529876. [CrossRef] [PubMed]

170. Waite, K.; Youssef, H. The Role of Neoadjuvant and Adjuvant Systemic Chemotherapy with Cytoreductive Surgery and Heated Intraperitoneal Chemotherapy for Colorectal Peritoneal Metastases: A Systematic Review. Ann. Surg. Oncol. 2017, 24, 705-720. [CrossRef] [PubMed]

171. Mas-Fuster, M.I.; Ramon-Lopez, A.; Nalda-Molina, R. Importance of standardizing the dose in hyperthermic intraperitoneal chemotherapy (HIPEC): A pharmacodynamic point of view. Cancer Chemother. Pharmacol. 2013, 72, 273-274. [CrossRef] [PubMed]

172. Schaaf, L.; van der Kuip, H.; Zopf, W.; Winter, S.; Münch, M.; Mürdter, T.E.; Thon, K.P.; Steurer, W.; Aulitzky, W.E.; Ulmer, C. A Temperature of 40 degrees C Appears to be a Critical Threshold for Potentiating Cytotoxic Chemotherapy In Vitro and in Peritoneal Carcinomatosis Patients Undergoing HIPEC. Ann. Surg. Oncol. 2015, 22 (Suppl. S3), S758-S765. [CrossRef]

173. Kyang, L.S.; Alzahrani, N.A.; Zhao, J.; Morris, D.L. Gastric perforation following cytoreductive surgery and perioperative intraperitoneal chemotherapy: A case series of six. World J. Surg. Oncol. 2017, 15, 44. [CrossRef] [PubMed]

174. Zappa, L.; Savady, R.; Sugarbaker, P.H. Gastric perforation following cytoreductive surgery with perioperative intraperitoneal chemotherapy. J. Surg. Oncol. 2010, 101, 634-636. [CrossRef]

175. De Somer, F.; Ceelen, W.; Delanghe, J.; De Smet, D.; Vanackere, M.; Pattyn, P.; Mortier, E. Severe hyponatremia, hyperglycemia, and hyperlactatemia are associated with intraoperative hyperthermic intraperitoneal chemoperfusion with oxaliplatin. Perit. Dial. Int. 2008, 28, 61-66.

176. Tan, G.H.C.; Shannon, N.B.; Chia, C.S.; Soo, K.C.; Teo, M.C.C. Platinum agents and mitomycin C-specific complications in cytoreductive surgery (CRS) and hyperthermic intraperitoneal chemotherapy (HIPEC). Int. J. Hyperth. 2018, 34, 595-600. [CrossRef] [PubMed] 